OPEN ACCESS

Edited by:

Gunes Ozhan,

Dokuz Eylül University, Turkey

Reviewed by:

Alexey Koval,

University of Geneva, Switzerland

Gary Davidson,

Karlsruhe Institute of Technology

(KIT), Germany

*Correspondence:

Eek-hoon Jho

ej70@uos.ac.kr

Specialty section:

This article was submitted to

Signaling,

a section of the journal

Frontiers in Cell and Developmental

Biology

Received: 25 May 2021

Accepted: 25 August 2021

Published: 13 September 2021

Citation:

Jeong $W$ and Jho E-h (2021)

Regulation of the Low-Density

Lipoprotein Receptor-Related Protein

LRP6 and Its Association With

Disease: Wnt/ $\beta$-Catenin Signaling

and Beyond.

Front. Cell Dev. Biol. 9:714330.

doi: 10.3389/fcell.2021.714330

\section{Regulation of the Low-Density Lipoprotein Receptor-Related Protein LRP6 and Its Association With Disease: Wnt/3-Catenin Signaling and Beyond}

\author{
Wonyoung Jeong and Eek-hoon Jho* \\ Department of Life Science, University of Seoul, Seoul, South Korea
}

Wnt signaling plays crucial roles in development and tissue homeostasis, and its dysregulation leads to various diseases, notably cancer. Wnt/ $\beta$-catenin signaling is initiated when the glycoprotein Wnt binds to and forms a ternary complex with the Frizzled and low-density lipoprotein receptor-related protein 5/6 (LRP5/6). Despite being identified as a Wnt co-receptor over 20 years ago, the molecular mechanisms governing how LRP6 senses Wnt and transduces downstream signaling cascades are still being deciphered. Due to its role as one of the main Wnt signaling components, the dysregulation or mutation of LRP6 is implicated in several diseases such as cancer, neurodegeneration, metabolic syndrome and skeletal disease. Herein, we will review how LRP6 is activated by Wnt stimulation and explore the various regulatory mechanisms involved. The participation of LRP6 in other signaling pathways will also be discussed. Finally, the relationship between LRP6 dysregulation and disease will be examined in detail.

Keywords: LRP6, Wnt, cancer, metabolism, signaling

\section{INTRODUCTION}

Wnt signaling has crucial roles in development and tissue homeostasis (Nusse and Clevers, 2017). The interaction between Wnt, Frizzled, and lipoprotein receptor-related protein 5/6 (LRP5/6) activates Wnt signaling. If the main output of Wnt signaling activation is stabilization of the transcriptional activator $\beta$-catenin, the pathway is known as canonical Wnt or Wnt/ $\beta$-catenin signaling (hereafter referred to as "Wnt/ $\beta$-catenin signaling"). In the absence of Wnt, the scaffold protein Axin together with adenomatous polyposis coli (APC), glycogen synthase kinase $3 \beta$ (GSK3 $\beta$ ), and casein kinase 1 alpha (CK1 $\alpha)$ form the so called destruction complex that binds cytoplasmic $\beta$-catenin, leading to its phosphorylation by CK1 $\alpha$ and GSK3 $\beta$. Phosphorylated $\beta$-catenin is ubiquitinated by the $\mathrm{SCF}^{\beta-\operatorname{Trcp}} \mathrm{E} 3$ ubiquitin ligase complex, a process that targets it for proteasomal degradation (Aberle et al., 1997; Kitagawa et al., 1999; Liu et al., 2002). In the presence of Wnt, the $\beta$-catenin destruction complex is recruited to the plasma membrane 
and inactivated (Figure 1A). As a result, $\beta$-catenin is stabilized and then translocates to the nucleus to activate the expression of target genes involved in cell proliferation, differentiation, stem cell self-renewal and many other biological processes (MacDonald et al., 2009). In non-canonical Wnt signaling, Wnt (e.g., Wnt5a) transduces signaling without $\beta$-catenin stabilization by activating alternative downstream cascades such as JUN kinase, planar cell polarity (PCP), or calcium signaling (Kikuchi et al., 2009). It is well known that dysregulation of Wnt signaling causes developmental disorders and several diseases such as cancer (Nusse and Clevers, 2017). Notably, hyper-activation of $\beta$-catenin, due to mutations in APC, AXIN, or CTNNB1 (gene for $\beta$-catenin), is a well-known risk factor for carcinogenesis, especially colon cancer (Bugter et al., 2021).

The type I single transmembrane protein LRP6 is a member of the LDLR gene family of receptors that is highly conserved among species (Pinson et al., 2000; Tamai et al., 2000; Wehrli et al., 2000). The extracellular region of LRP6 contains four YWTD (TyrTrp-Thr-Asp)-type $\beta$-propellers, followed by EGF-like domains (E1-E4), and three LDLR type A domains (Cheng et al., 2011), and its intracellular region contains five PPPS/TP (Pro-ProPro-Ser/Thr-Pro) motifs (Tamai et al., 2004). Formation of the Wnt-FZD-LRP6 ternary complex at the plasma membrane (i.e., Wnt-on state) induces phosphorylation of the intracellular region of LRP6 (MacDonald and He, 2012). Phosphorylation of LRP6 is therefore considered a hallmark of $\mathrm{Wnt} / \beta$-catenin signaling activation. Contrary to Wnt, the secreted Wnt modulator Dickkopf (Dkk) binds to LRP6 and promotes its membrane clearance, thereby functioning as an LRP6 antagonist (Mao B. et al., 2001; Mao et al., 2002). Owing to its importance in $\mathrm{Wnt} / \beta$-catenin signaling transduction, mutation or dysregulation of LRP6 is implicated in several diseases (Joiner et al., 2013). LRP5, which is a paralog of LRP6 and shares 71\% sequence conservation (Tamai et al., 2000), plays a similar role as LRP6 in transducing Wnt/ $\beta$-catenin signaling (Mao J. et al., 2001); however, the biological functions of LRP6 and LRP5 differ significantly (Joiner et al., 2013). In this review we will mainly focus on LRP6. We will describe the molecular mechanisms governing Wnt-dependent LRP6 activation, and discuss how LRP6 function is regulated by various factors. We will also discuss LRP6's role in the regulation of downstream $\mathrm{Wnt} / \beta$-catenin signaling, provide examples of its involvement in Wnt/ $\beta$-cateninindependent pathways, and illustrate how dysregulation or mutation of LRP6 can lead to several diseases.

\section{CORE MECHANISMS OF LRP6 ACTIVATION VIA Wnt STIMULATION}

In 2000, LRP6 was identified as a co-receptor for Wnt and FZD to transduce $W n t / \beta$-catenin signaling (Pinson et al., 2000; Tamai et al., 2000; Wehrli et al., 2000). The extracellular domain of LRP6 interacts with $\mathrm{Wnt}$ and activates $\mathrm{Wnt} / \beta$-catenin signaling at the plasma membrane. LRP6 with a truncated extracellular domain is constitutively active and can potentiate $\mathrm{Wnt} / \beta$-catenin signaling independently of Wnt (Liu et al., 2003). Conversely, LRP6 with a truncated intracellular domain acts as a dominant-negative form, inhibiting Wnt/ $\beta$-catenin signaling (Tamai et al., 2000). There are five PPPS/TP motifs in the LRP6 intracellular domain, and the serine/threonine residues in these motifs are phosphorylated upon Wnt stimulation (Tamai et al., 2004). GSK3 $\beta$ and CK1 $\gamma$ are the main kinases that phosphorylate the PPPS/TP motifs and their flanking regions, respectively (Davidson et al., 2005; Zeng et al., 2005). Dishevelled (DVL) proteins are essential for Wntinduced LRP6 aggregation with FZD, and the complex formed between LRP6, FZD, and DVL relies on the DIX and PDZ domains of DVL (Zeng et al., 2008; Figure 1B). In the Wnton state, additional $\mathrm{Wnt} / \beta$-catenin signaling components such as Axin, CK1 $\alpha$, and GSK3 $\beta$ form a complex with LRP6 known as the signalosome (Bilic et al., 2007). Signalosome formation leads to further LRP6 phosphorylation by GSK3 $\beta$ that in turn promotes more aggregation of Wnt/ $\beta$-catenin signaling components (Zeng et al., 2008). The end result is increased dissociation of $\beta$-catenin away from the destruction complex, allowing it to accumulate in the cytoplasm and then translocate to the nucleus (Cselenyi et al., 2008; Wu et al., 2009). Wnt3a-induced activation of LRP6 is rapid, and aggregation of components involved in Wnt/ $\beta$-catenin signaling can be observed as early as $30 \mathrm{~min}$ by live cell imaging (Bilic et al., 2007). Another important player in the signalosome is PIP5K1, a phosphatidylinositol phosphate kinase whose activation is mediated by FZD and DVL (Pan et al., 2008). Activation of PIP5K1 leads to production of phosphatidylinositol 4,5-bisphosphate ( $\left.\operatorname{ptdIns}(4,5) \mathrm{P}_{2}\right)$, which in turn induces aggregation and phosphorylation of LRP6 (Pan et al., 2008; Figure 1C). Hence, non-protein components such as phospholipids can also play crucial roles in LRP6-mediated $\mathrm{Wnt} / \beta$-catenin signaling.

\section{REGULATION OF LRP6 FUNCTION AND DOWNSTREAM SIGNALING}

\section{Phosphorylation}

As described above, in the presence of Wnt, the five PPPS/TP motifs in the intracellular domain of LRP6 are mainly phosphorylated by GSK $3 \beta$ and CK $1 \gamma$. However, additional ligands, kinases or interacting proteins have also been shown to regulate LRP6 phosphorylation and thus influence $\mathrm{Wnt} / \beta$-catenin signaling. First, we review how these components affect LRP6 phosphorylation and positively regulate Wnt $/ \beta$-catenin signaling. Similar to GSK $3 \beta$, G protein-coupled receptor kinases 5 and 6 (GRK5/6), mitogen-activated protein kinases (MAPKs), such as p38, extracellular signal regulated kinase 1 and $2(\mathrm{ERK} 1 / 2)$, and c-Jun N-terminal kinases 1 (JNK1) also interact with LRP6 and induce phosphorylation of its PPPS/TP motifs (Chen et al., 2009; Červenka et al., 2011; Figure 2). For example, fibroblast growth factor 2 (FGF2)induced ERK activation leads to phosphorylation of the S1490 or T1572 residues of LRP6, resulting in Wnt/ $\beta$-catenin signaling activation (Krejci et al., 2012). Parathyroid hormone (PTH), a crucial factor for bone formation, acts as another LRP6 regulator by forming a ternary complex with PTH1 receptor (PTH1R) and LRP6 to facilitate PPPS/TP phosphorylation (Wan et al., 2008). In addition, several proteins interact with LRP6 and thereby 


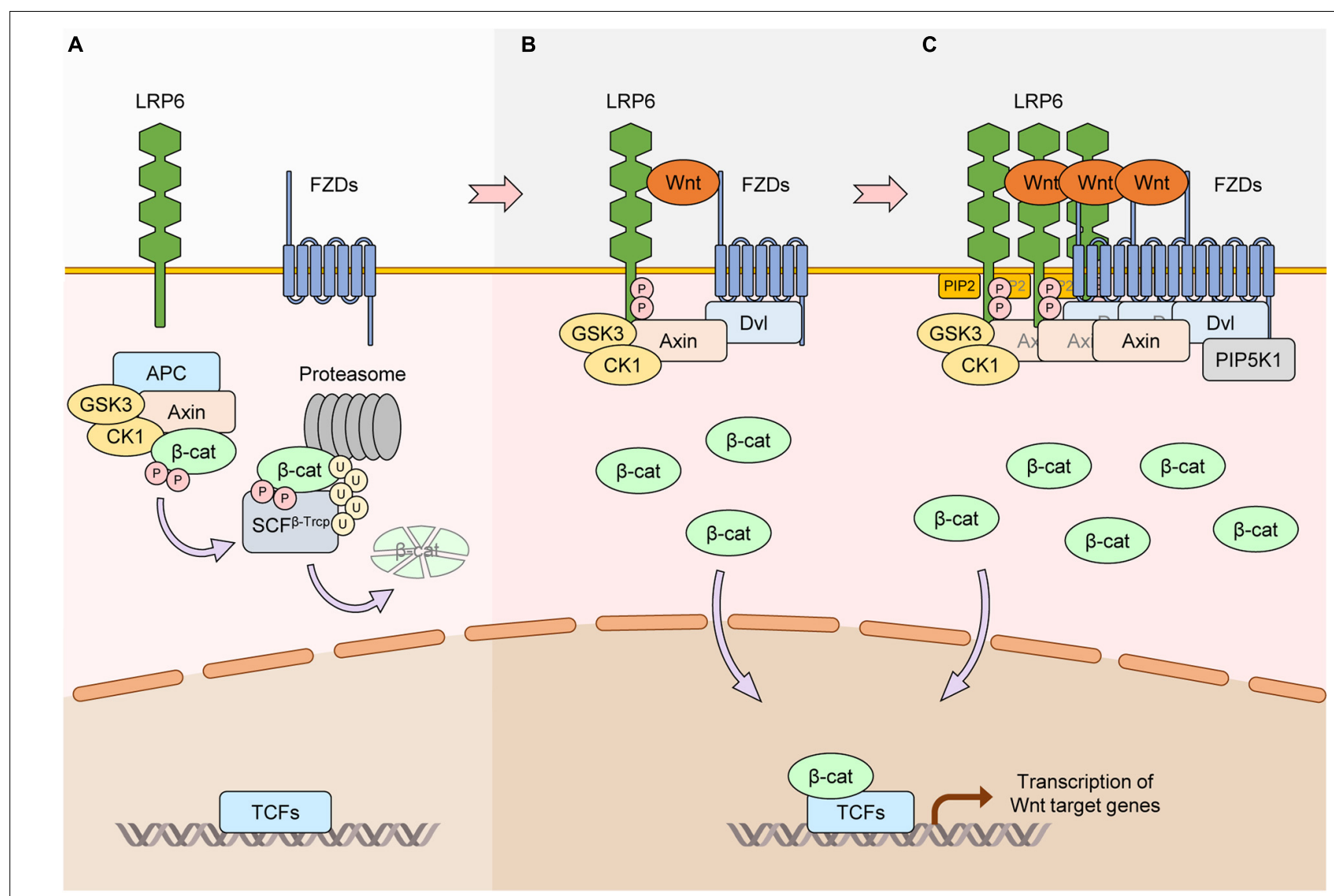

FIGURE 1 | Core activation mechanisms of LRP6 via Wnt stimulation. (A) In the absence of Wnt, the scaffold protein Axin together with APC, GSK3, and CK1 form the $\beta$-catenin destruction complex. $\beta$-catenin interacts with the complex and is phosphorylated by GSK3 and CK1 $\alpha$ (CK1). Phosphorylated $\beta$-catenin is ubiquitinated by SCF $\beta$-Trcp and degraded by the proteasome. Protein levels of $\beta$-catenin thus remain low, and $\beta$-catenin-dependent transcription of Wnt/ $\beta$-catenin target genes is suppressed. (B) Wnt interacts with the FZD and LRP6 receptors. Axin-bound GSK3 and CK1 $\gamma$ phosphorylate PPPS/TP motifs in the intracellular domain of LRP6. Phosphorylated LRP6 serves as a docking site for Axin, facilitating the interaction between Axin and LRP6 and inhibiting the kinase activity of GSK3. This causes the dissociation and inactivation of the $\beta$-catenin destruction complex, leading to $\beta$-catenin stabilization and activation of Wnt/ $\beta$-catenin target gene transcription. (C) Treatment of Wnt induces LRP6 aggregates in a DVL-dependent manner. In this condition, FZDs, Axin, and GSK3 can also aggregate with LRP6, generating LRP6 signalosomes. PIP 2 is generated via DVL-bound PIP5K1. PIP 2 accelerates the formation of LRP6 signalosomes and phosphorylation of LRP6, resulting in further activation of $\mathrm{Wnt} / \beta$-catenin signaling.

enhance its phosphorylation and $\mathrm{Wnt} / \beta$-catenin signaling by modulating LRP6 localization or acting as a scaffold for LRP6 and other Wnt components. For instance, the G protein $G \beta_{1} \gamma_{2}$ promotes GSK3 localization to the plasma membrane, which in turn promotes LRP6 phosphorylation (Jernigan et al., 2010). DVL is well-known for playing a crucial role in signalosome formation. Ectopic expression of the DVL DIX domain fused to the LRP6 intracellular domain promotes Wnt/B-catenin signaling via formation of cytoplasmic signalosomes and induction of LRP6 phosphorylation, suggesting that stable LRP6-DVL interactions are essential for the maintenance of LRP6 phosphorylation (Metcalfe et al., 2010). Interestingly, transmembrane protein 198 (TMEM198), a previously uncharacterized seven-transmembrane protein, acts as a scaffold protein for CK1 $\gamma$ and LRP6 (Liang et al., 2011) and thus enhances phosphorylation of LRP6 (Figure 2).

Changes in plasma membrane lipid composition can also affect the phosphorylation of LRP6 and subsequent
Wnt $/ \beta$-catenin signaling activation. APC membrane recruitment protein 1 (Amer1) translocates to the plasma membrane in a PtdIns $(4,5) \mathrm{P}_{2}$-dependent manner, where it recruits Axin, CK1 $\gamma$, and GSK3 $\beta$ to promote LRP6 phosphorylation (Tanneberger et al., 2011). ADP-ribosylation factors 1 and 6 (Arf1/6) switch to the GTP-bound active form upon Wnt3a treatment, which facilitates the production of PtdIns $(4,5) \mathrm{P}_{2}\left(\mathrm{PIP}_{2}\right)$ and subsequent LRP6 phosphorylation (Kim W. et al., 2013). LY6/PLAUR domain-containing 6 protein (Lypd6) interacts with LRP6 and induces its localization to lipid rafts (Özhan et al., 2013). A lipid raft is a specific region in the plasma membrane where lipid components such as sphingolipid and cholesterol are enriched and cellular signaling is activated (Sezgin et al., 2017). Therefore Lypd6 potentiates LRP6 phosphorylation and activates $\mathrm{Wnt} / \beta$-catenin signaling (Figure 2).

Next, we review other proteins that influence LRP6 phosphorylation and negatively regulate Wnt/B-catenin signaling. In contrast to CK1 $\gamma$, whose phosphorylation of LRP6 
enhances $W n t / \beta$-catenin signaling, $C K 1 \varepsilon$ inhibits $W n t / \beta$-catenin signaling by interacting with and phosphorylating LRP6 at the S1420 and S1430 residues that are not present in PPPS/TP motifs (Swiatek et al., 2006; Figure 2). Moreover, Src and Fer tyrosine kinases phosphorylate LRP6 tyrosine residues near the PPPS/TP motifs, which leads to reduction of LRP6 cell surface levels and blockage of signalosome formation (Chen et al., 2014). It has been shown that several ligands for LRP6 inhibit its phosphorylation and suppress Wnt/ $\beta$-catenin signaling. Wnt5a is mainly involved in noncanonical Wnt signaling. However, by recruiting Wnt receptors away from canonical Wnts (e.g., Wnt3a), Wnt5a can inhibit the phosphorylation of LRP6 and therefore act as a negative regulator of Wnt/ $\beta$-catenin signaling (Grumolato et al., 2010; Sato et al., 2010). Pigment epithelium-derived factor (PEDF) interacts with the extracellular domain of LRP6, inhibiting LRP6-FZD interaction and phosphorylation of LRP6 (Park et al., 2011). Protein interactions in the intracellular region of LRP6 also mediate the inhibition of LRP6 phosphorylation. Merlin, a main player in the Hippo signaling pathway, interacts with LRP6 and inhibits its phosphorylation (Kim et al., 2016). Merlininduced inhibition of LRP6 phosphorylation is counteracted by Wnt3a treatment, which, by inducing phosphorylation of merlin through P21 activated kinase 1 (PAK1), promotes merlin dissociation from LRP6 (Kim et al., 2016; Figure 2). Overall, these studies suggest that several proteins, by acting as kinases, ligands, or binding partners for LRP6, are crucial for regulating LRP6 phosphorylation and Wnt/ $\beta$-catenin signaling, either in a positive or negative manner.

\section{Internalization}

Receptor-mediated internalization plays a crucial role in signal transduction. LRP6 is internalized after binding to ligands, and internalized LRP6 can either positively or negatively regulate $\mathrm{Wnt} / \beta$-catenin signaling. For instance, the secreted Wnt modulator Dkk1, by forming a ternary complex with the single transmembrane protein Kremen $1 / 2$ and LRP6, internalizes LRP6 and decreases its plasma membrane levels, leading to Wnt/ $\beta$-catenin signaling inhibition (Bafico et al., 2001; Mao B. et al., 2001; Semënov et al., 2001; Mao et al., 2002; Figure 3A). Internalization of LRP6 via Dkk1 also leads to decreased LRP6 phosphorylation by CK1 $\gamma$ (Sakane et al., 2010). Angiopoietinlike 4 protein (ANGPTL4) is another secretory protein that, by forming a complex with syndecan and LRP6, induces LRP6 internalization and decreases its surface levels (Kirsch et al., 2017). Similar to ANGPTL4, the secretory protein Bighead interacts with LRP6 and promotes its endocytosis and lysosomal degradation, resulting in suppression of $\mathrm{Wnt} / \beta$-catenin signaling (Ding et al., 2018). Glycosylation of LRP6 can also influence its internalization. LRP6 can be fucosylated, a process that promotes the internalization of lipid raft-localized LRP6. This process prevents formation of the Wnt-FZD-LRP6 complex and thus inhibits Wnt/ $\beta$-catenin signaling (Hong et al., 2020; Figure 3A). Wnt-activated inhibitory factor 1 protein (Waif1), a transmembrane protein, interacts with LRP6 and inhibits Wnt3ainduced LRP6 internalization into endocytic vesicles, thereby

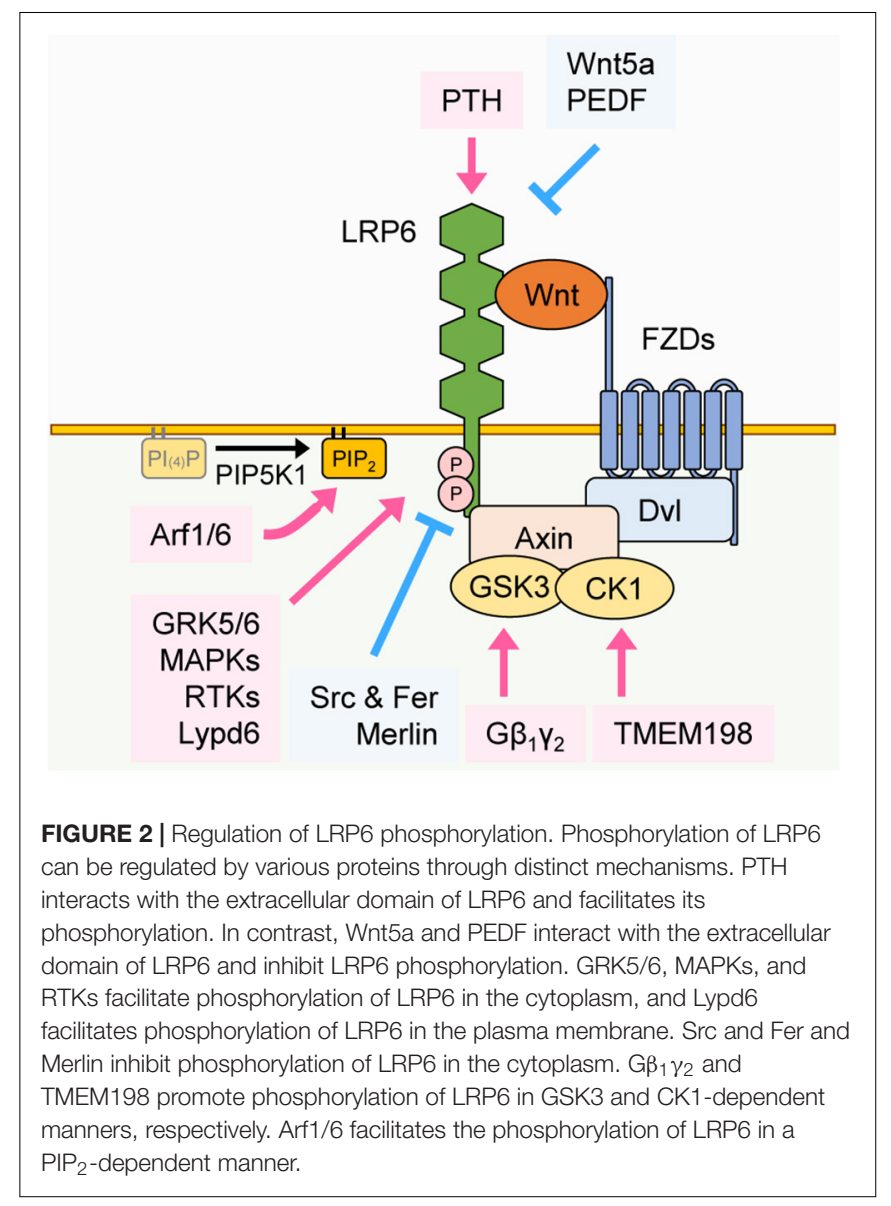

reducing Wnt/ $\beta$-catenin signaling (Kagermeier-Schenk et al., 2011; Figure 3B).

Clathrin, a protein with a prominent role in cellular vesicle formation, promotes Dkk-mediated LRP6 internalization and thus acts as a negative regulator $\mathrm{Wnt} / \beta$-catenin signaling (Yamamoto et al., 2008). Interestingly, clathrin can also promote LRP6 internalization in the presence of Wnt. This is because Wnt3a treatment, by inducing S1579 phosphorylation of LRP6, enhances LRP6 binding to disabled-2 (Dab2), an interaction that promotes clathrin-mediated LRP6 internalization (Jiang et al., 2012). Similar to Dab2, long-term treatment of Wnt3a (6-8 h) induces phosphorylation of adaptor related protein complex 2 subunit mu 1 (AP2M1) through AP2-associated kinase 1 (AAK1), and phosphorylated AP2M1 activates clathrin-mediated LRP6 internalization, once again leading to negative regulation of Wnt/ $\beta$-catenin signaling (Agajanian et al., 2019). Therefore Dab2 and AAK1 seem to alleviate hyper-activation of $\mathrm{Wnt} / \beta$-catenin signaling induced by Wnt stimulation (Figure 3A). Whereas clathrin is known for having a role in internalization of LRP6 and inhibition of $\mathrm{Wnt} / \beta$-catenin signaling, it is reported that clathrin and AP2 act as components of the LRP6 signalosome, being recruited to the signalosome in a PtdIns $(4,5) \mathrm{P}_{2}$-dependent manner (Kim I. et al., 2013). In this context, clathrin and AP2 seem to play a role in cell surface signalosome formation for activation of $\mathrm{Wnt} / \beta$-catenin signaling, as well as in LRP6 
A

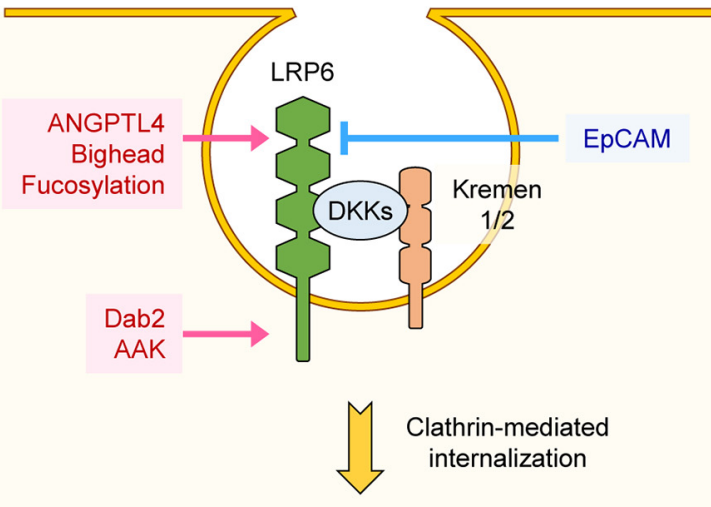

Degradation \& inhibition of LRP6<smiles>C1NC2CC12</smiles>

Inhibition of Wnt signaling
B

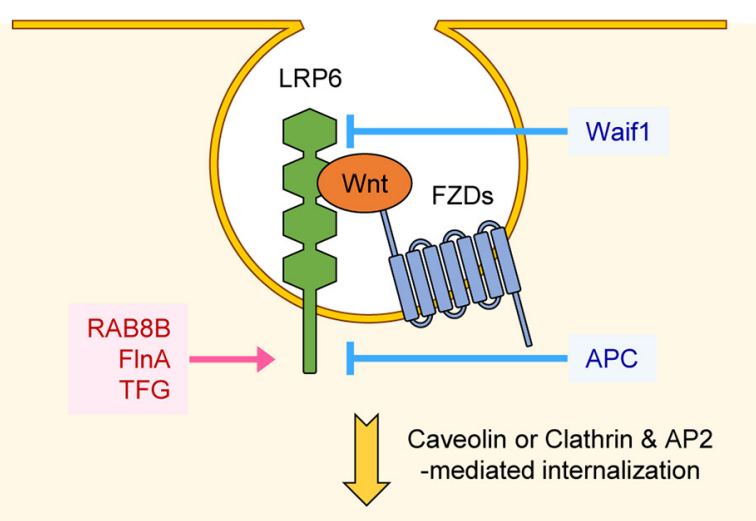

MVB formation \& activation of LRP6<smiles>C1NC2CC12</smiles>

Activation of Wnt signaling

FIGURE 3 | Regulation of LRP6 internalization. (A) Interaction between LRP6, DKKs, and Kremen1/2 promotes clathrin-mediated internalization, resulting in degradation or inhibition of LRP6. ANGPTL4, Bighead, and fucosylation of LRP6 promotes internalization of LRP6 at the extracellular level, thereby inhibiting LRP6 function and Wnt/ $\beta$-catenin signaling. Dab2 and AAK function at the intracellular level and promote clathrin-mediated internalization of LRP6, resulting in Wnt/B-catenin signaling suppression. On the other hand, EpCAM inhibits LRP6-DKK-Kremen1/2 complex formation, resulting in Wnt signaling activation. (B) Interaction among LRP6, FZDs, and Wnt promotes caveolin-mediated internalization, resulting in LRP6 activation and MVB formation. RAB8B, FinA, and TFG promote Wnt3a-mediated internalization of LRP6 and Wnt/ $\beta$-catenin signaling at the intracellular level. However, Waif1 compromises Wnt-LRP6 interaction and inhibits Wnt/ $\beta$-catenin signaling. APC inhibits Clathrin and AP2-mediated internalization of LRP6 at the intracellular level, resulting in suppression of Wnt/ $\beta$-catenin signaling.

internalization. Interestingly, it is reported that APC, a main component of the $\beta$-catenin destruction complex, is also involved in LRP6 internalization. APC directly interacts with clathrin and AP2 to inhibit clathrin-induced LRP6 internalization, a process that generally leads to constitutive ligand-independent Wnt/ $\beta$-catenin activation (Saito-Diaz et al., 2018). APC thus blocks $W n t / \beta$-catenin signaling in two different contexts: in the cytoplasm, by forming destruction complex, and in the plasma membrane, by preventing LRP6 internalization (Saito-Diaz et al., 2018; Figure 3B).

It is well known that several components positively regulate Wnt/ $\beta$-catenin signaling by modulating internalization of LRP6. Epithelial-cell-adhesion molecule (EpCAM) interacts with Kremen1 and inhibits Kremen1-Dkk2-LRP6 complex formation and internalization, resulting in activation of $\mathrm{Wnt} / \beta$-catenin signaling ( $\mathrm{Lu}$ et al., 2013; Figure 3A). In the presence of Wnt, LRP6 together with FZD, Axin, and GSK3 $\beta$ are internalized in caveolin-enriched vesicles (Yamamoto et al., 2006). GSK3 $\beta$ is sequestered in complex with LRP6 in multivesicular bodies (MVBs) and vastly reduces its phosphorylation of $\beta$-catenin, leading to activation of $\mathrm{Wnt} / \beta$-catenin signaling (Taelman et al., $2010)$. There are many components involved in the activation of Wnt/ $\beta$-catenin signaling via internalization of LRP6. These include Rab GTPase RAB8B protein and actin-binding protein filamin A (FlnA), both of which promote caveolin-mediated LRP6 internalization (Demir et al., 2013; Lian et al., 2016). Upon Wnt3a treatment, RAB8B interacts with LRP6 and is recruited to the signalosome complex, where it enhances caveolin-mediated internalization of LRP6 and subsequent Wnt/ $\beta$-catenin signaling activation (Demir et al., 2013). FlnA interacts with LRP6, and loss of FlnA impairs internalization of LRP6 and activation of $\mathrm{Wnt} / \beta$-catenin signaling, resulting in decreased proliferation of neural progenitor cells (Lian et al., 2016; Figure 3B). Recently, LRP6 proximity proteins induced upon short-term Wnt3a treatment were identified using an LRP6-Apex2 fusion protein (Colozza et al., 2020). Among them, Trk fused gene protein (TFG) appears to have an important role in Wnt3a-mediated LRP6 internalization and activation of $\mathrm{Wnt} / \beta$-catenin signaling (Colozza et al., 2020; Figure 3B).

\section{Regulation of LRP6 Maturation and Stability}

Proper folding and maturation are essential for LRP6 to carry out its functions at the plasma membrane, and there are several components involved in these processes. Although mature LRP6 is known to be a stable protein (Perrody et al., 2016), its stability can be altered by extracellular stimuli or regulatory factors. Mesoderm development LRP chaperone protein (Mesd) localizes to the endoplasmic reticulum (ER), where it enhances the maturation and plasma membrane localization of LRP6 (Hsieh et al., 2003; Figure 4). Several proteins are involved in Mesd-mediated maturation of LRP6. The ER heat shock protein Grp94 promotes interaction between LRP6 and Mesd, and Grp94-deficiency suppresses LRP6 maturation (Liu et al., 2013). The transmembrane glycoprotein CD44 interacts with 


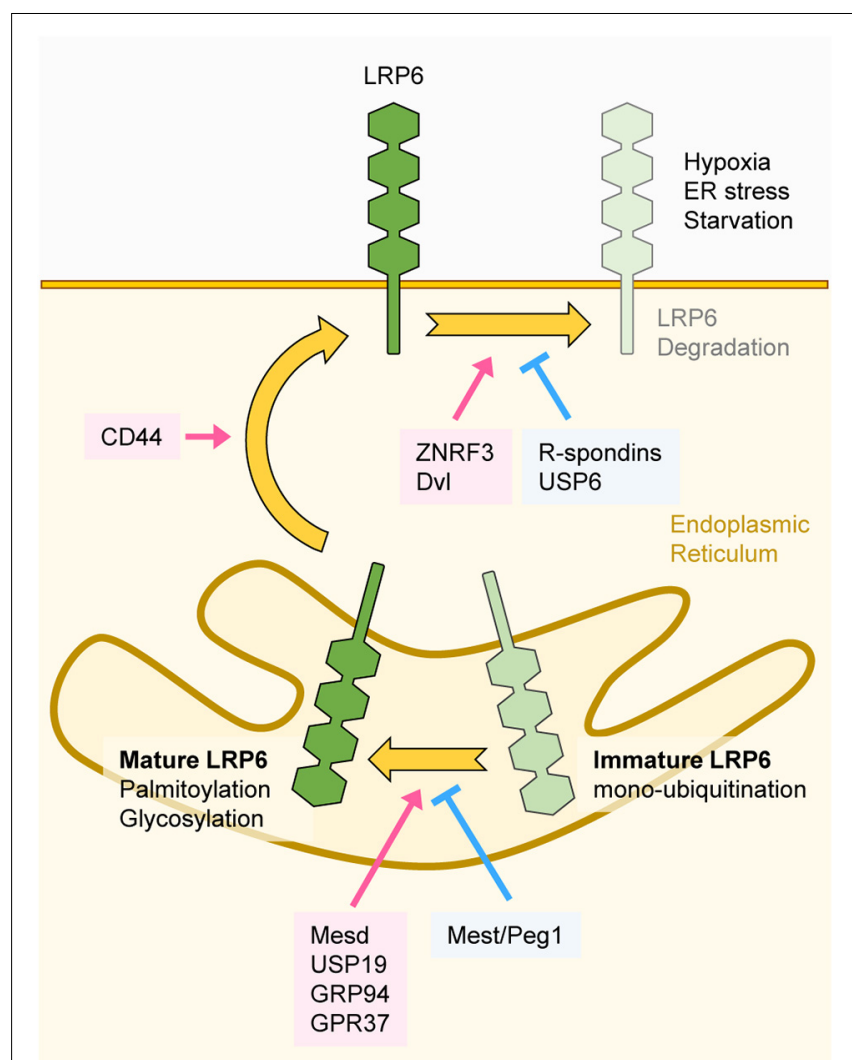

FIGURE 4 | Regulation of LRP6 maturation and stability. The transmembrane protein LRP6 undergoes several folding and maturation processes to translocate to the plasma membrane and properly function as a Wnt co-receptor. Mesd, USP19, GRP94, and GPR37 promote proper folding of LRP6. Glycosylation and palmitoylation of LRP6 are essential for its maturation. Mest/Peg1 inhibits glycosylation of LRP6 and immature LRP6 is mono-ubiquitinated, resulting in ER retention. Folded and mature LRP6 localizes to the plasma membrane, and CD44 promotes membrane localization of LRP6. ZNRF3 and DVL downregulate LRP6 protein levels, and USP6 and R-spondins antagonize ZNRF3 function. Extracellular stimuli such as hypoxia, ER stress, and starvation also degrade LRP6.

LRP6 and promotes Mesd-mediated membrane localization of LRP6 (Schmitt et al., 2015). The Parkinson's disease-associated receptor (GPR37) acts as an additional chaperone for LRP6 and promotes the maturation and membrane localization of LRP6. Additionally, GPR37 also inhibits ER-associated degradation of LRP6 and thereby enhances the protein levels of LRP6 (Berger et al., 2017).

Post-translational modifications (PTMs) have also been found to be important for regulating LRP6 folding and maturation. By using an endogenous antibody against LRP6, it has been found that LRP6 is N-glycosylated, and that N-glycosylation is necessary for the membrane localization of LRP6 (Khan et al., 2007). On the other hand, mesoderm-specific transcript/paternally expressed gene 1 (Mest/Peg1) represses glycosylation and plasma membrane localization of LRP6 (Jung et al., 2011), resulting in repression of $\mathrm{Wnt} / \beta$-catenin signaling. Moreover, palmitoylation on a juxtamembrane cysteine of LRP6 enables its translocation from the ER to the plasma membrane (Abrami et al., 2008;
Figure 4). If this process is hindered, mono-ubiquitination on the K1403 residue of LRP6 is promoted, leading to ER retention (Abrami et al., 2008). Further studies revealed that LRP6 monoubiquitination can be negatively regulated by the deubiquitinase USP19. Deubiquitination of LRP6 by USP19 facilitates LRP6 translocation to the plasma membrane through proper folding and palmitoylation (Perrody et al., 2016).

The R-spondin family members are secreted proteins that influence LRP6 stability (Wei et al., 2007). R-spondins are high affinity ligands for the Leucine-rich repeat-containing G-protein coupled receptors $4 / 5$ (LGR4/5) and the transmembrane E3 ubiquitin ligases ZNRF3/RNF43 (Carmon et al., 2011; Hao et al., 2012; Koo et al., 2012). In the absence of R-spondins, ZNRF3/RNF43 ubiquitinate Wnt receptors and promote their clearance from the plasma membrane. Binding of R-spondins to LGR4/5 and ZNRF3/RNF43 induces ZNRF3/RNF43 internalization, leading to Wnt receptor stabilization. R-spondins thus regulate the activity and phosphorylation of LRP6 by stabilizing it at the plasma membrane (Carmon et al., 2011; Hao et al., 2012; Koo et al., 2012). Further studies revealed that DVL recruits ZNRF3 to the plasma membrane and mediates ZNRF3-dependent downregulation of LRP6 (Jiang et al., 2015). Consistently, upregulation LRP6 protein levels was observed in DVL1/2/3 knockout cells, owing to lack of LRP6 plasma membrane clearance by ZNRF3 (Jiang et al., 2015). Therefore, DVL seems to have dual role in the regulation of $\mathrm{Wnt} / \beta$-catenin signaling since it promotes both aggregation and destabilization of LRP6 at the plasma membrane. Contrary to ZNRF3, the deubiquitinase USP6 increases LRP6 membrane levels and potentiates $\mathrm{Wnt} / \beta$-catenin signaling by antagonizing the function of ZNRF3 (Madan et al., 2016).

Cellular stress can influence LRP6 stability. Chemically induced ER stress or hypoxia reduces the stability of LRP6, resulting in inhibition of $\mathrm{Wnt} / \beta$-catenin signaling (Xia et al., 2019). Moreover, O-GlcNAcylation, a PTM that induces the attachment of $\mathrm{N}$-acetylglucosamine (GlcNAc) to Ser/Thr residues, also plays a crucial role in LRP6 stability. During serum starvation, O-GlcNAcylation of LRP6 is reduced, which is followed by lysosomal degradation of LRP6 (Jeong et al., 2020; Figure 4).

\section{$\beta$-CATENIN-INDEPENDENT SIGNALING VIA ACTIVATION OF LRP6}

It is generally assumed that the primary output of LRP6 activity is directly associated with alterations in $\mathrm{Wnt} / \beta$-catenin signaling. However, several studies have revealed that LRP6 affects not only Wnt/ $\beta$-catenin signaling, but other signaling pathways as well. These include non-canonical Wnt signaling, Wntdependent stabilization of proteins (Wnt/STOP) signaling, G protein-coupled receptor (GPCR) and Hippo signaling.

The interaction of GPCR ligands with their associated receptors initiates GPCR signaling via activation of the $G$ protein $\mathrm{G} \alpha$, which mediates the activity of downstream effector proteins. LRP6 interacts with and promotes membrane localization of the $\mathrm{G}$ protein $\mathrm{G} \alpha_{\mathrm{s}}$ (Wan et al., 2011). Moreover, in the presence 

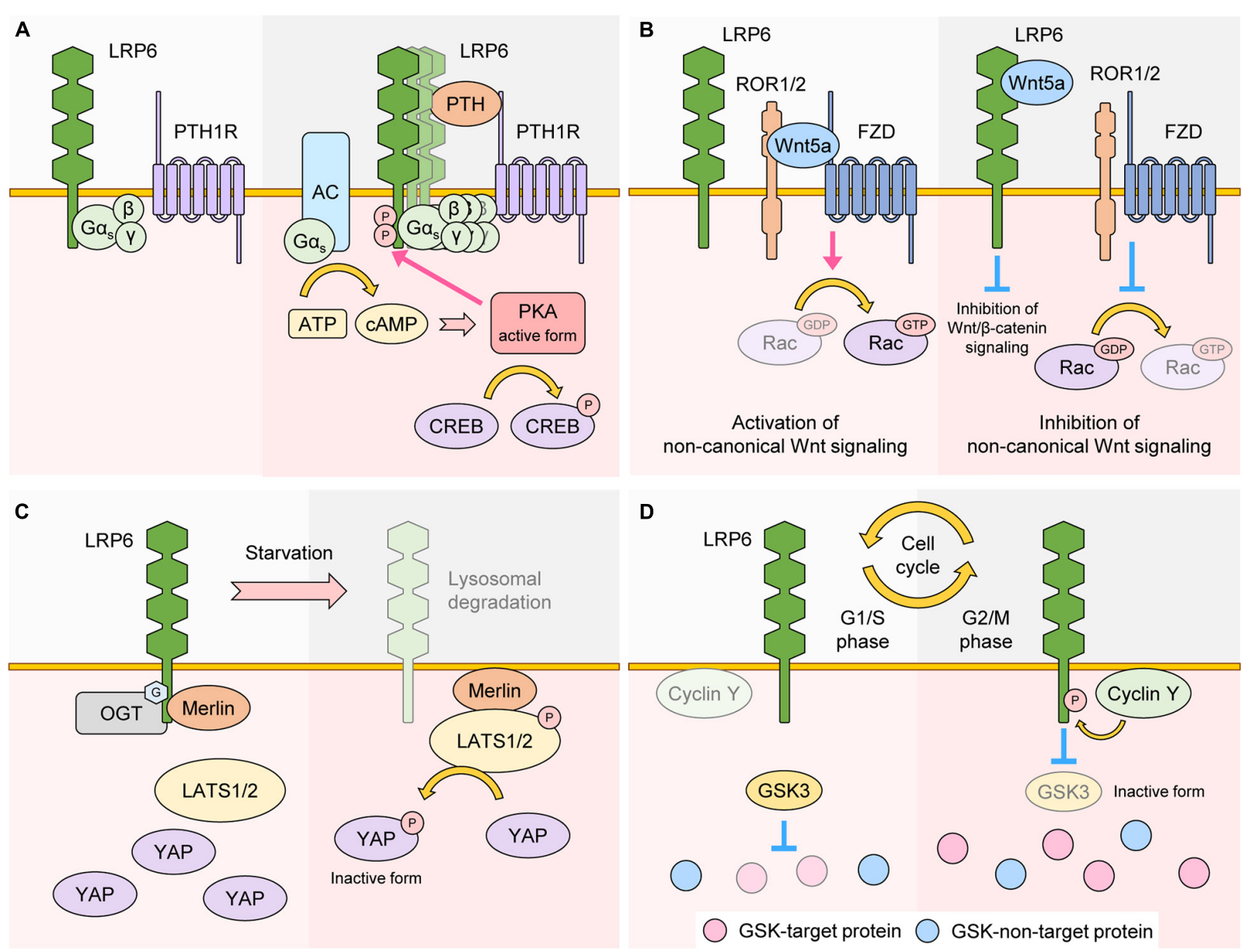

FIGURE 5 | Role of LRP6 as a regulator of other signaling. (A) LRP6 as a regulator of GPCR signaling. In the basal state, LRP6 interacts with G protein G $\alpha_{S}$. In the presence of the GPCR ligand PTH, a LRP6-PTH-PTH1R ternary complex is formed, which promotes aggregation of LRP6 and membrane localization of Gas. Production of CAMP is also upregulated in a G $\alpha_{s}$-AC-dependent manner. CAMP activates PKA, which promotes phosphorylation of LRP6 and CREB, two well-known downstream targets of PKA. (B) LRP6 as a regulator of non-canonical Wnt signaling. Wnt5a interacts with ROR1/2 and FZD, resulting in activation of Rac, a non-canonical Wnt signaling target. Wnt5a can also interact with LRP6. In these conditions, the binding affinity of ROR1/2 and FZD to Wnt5a is reduced. As a result, Rac becomes inactive and non-canonical Wnt signaling is inhibited. Because LRP6-Wnt5a binding weakens LRP6-Wnt3a interaction, Wnt/B-catenin signaling is also inhibited. (C) LRP6 as a regulator of Hippo signaling. In a nutrient rich state, LRP6 is O-GlcNAcylated and interacts with Merlin. In this condition, activity of LATS1/2 is maintained at low levels, resulting in stabilization and activation of YAP. In nutrient starvation conditions, O-GlcNAcylation and protein levels of LRP6 are both downregulated, and Merlin changes its binding partner from LRP6 to LATS1/2, resulting in activation of LATS1/2. YAP is phosphorylated by LATS1/2 and becomes inactive. (D) LRP6 as a regulator of Wnt/STOP signaling. In G1/S phase, cyclin $Y$ protein levels are less abundant and the phosphorylation state of LRP6 is low, resulting in higher GSK3 activity. GSK3-target proteins are thus phosphorylated and targeted for proteasomal degradation. In G2/M phase, cyclin Y protein levels peak and promote LRP6 phosphorylation, resulting in inactivation of GSK3 and stabilization of GSK3-target proteins.

of GPCR ligands such as PTH, LRP6 stimulates the production of cyclic AMP (cAMP) via $G \alpha_{s}$, and newly generated cAMP activates protein kinase a (PKA). Previous reports have shown that PTH facilitates LRP6 phosphorylation and activation of Wnt/ $\beta$-catenin signaling in osteoblasts (Wan et al., 2008), suggesting that LRP6 is involved in both, Wnt/ $\beta$-catenin and GPCR signaling, in the context of bone formation (Wan et al., 2011; Figure 5A).

The extracellular region of LRP6 interacts with Wnt5a, and this interaction inhibits activation of Rac1, a target protein of non-canonical Wnt signaling (Bryja et al., 2009). In addition, Wnt5a treatment interferes with the interaction between Wnt3a and LRP6, resulting in not only inhibition of $\mathrm{Wnt} / \beta$-catenin signaling, but activation of non-canonical Wnt signaling as well (Bryja et al., 2009; Grumolato et al., 2010; Figure 5B).

Hippo signaling is a crucial regulator of organ size and cellular homeostasis (Pan, 2010). Activation of Hippo signaling leads to serial phosphorylation and activation of STE20-like serine/threonine kinases $1 / 2 \quad(\mathrm{MST} 1 / 2)$ and Large Tumor Suppressor 1/2 (LATS1/2). Activated LATS1/2 phosphorylates Yes-associated protein (YAP) and WW domain containing transcription regulator protein 1 (TAZ). As a result, phosphorylated YAP and TAZ undergo 14-3-3mediated cytoplasmic retention or proteasomal degradation, a process which blocks their transcriptional activity and thereby inhibits cell proliferation and survival (Meng et al., 2016). 
It has been revealed that LRP6 is involved in the regulation of Hippo signaling. YAP/TAZ are incorporated into the $\beta$-catenin destruction complex, and treatment with Wnt3a or overexpression of LRP6 stabilizes the protein levels of YAP/TAZ in a similar fashion to $\beta$-catenin, leading to increased YAP/TAZ transcriptional activity (Azzolin et al., 2014). Another study revealed that loss of LRP6 via serum starvation promotes the dissociation of Merlin from LRP6, which activates Hippo signaling by facilitating Merlin-LATS interaction. As a result, loss of LRP6 enables phosphorylation of YAP, inhibiting its transcriptional activity (Jeong et al., 2020; Figure 5C).

Recent studies have shown that LRP6 phosphorylation peaks during the G2/M phase of the cell cycle and that this peak is dependent on cyclin $\mathrm{Y}$ and its cyclin dependent kinase 14 (CDK14). Originally, identified via kinome-wide RNAi screening in Drosophila cells, the cyclin Y-CDK14 complex phosphorylates the PPPS/TP S1490 residue of LRP6 (Davidson et al., 2009). Cyclin Y protein levels peak during G2/M, which explains the cell cycle dependence of LRP6 phosphorylation (Davidson et al., 2009). Mechanistically, G2/M phosphorylation of LRP6 by cyclin Y-CDK14 primes LRP6 for incoming Wnts, which in turn suppresses the activity of GSK3 and prevents GSK3 target proteins from proteasomal degradation (Taelman et al., 2010; Figure 2). Suppression of GSK3 during G2/M thus leads to an overall increase in protein stabilization, ensuring proper cell division and growth (Acebron et al., 2014). Importantly, this new Wnt sub-branch, also known as Wnt/STOP pathway, is completely dependent on LRP6 (Acebron et al., 2014; Acebron and Niehrs, 2016). Another player in the Wnt/STOP pathway is Caprin-2, which acts as a scaffold for LRP6 and cyclin Y and thereby promotes LRP6 phosphorylation during G2/M (Wang et al., 2016). Moreover, B-cell CLL/lymphoma 9 protein (BCL9) is phosphorylated at the $\mathrm{T} 172$ residue by cyclin dependent kinase 1 (CDK1), and phosphorylated BCL9 inhibits LRP6 degradation thereby acting as a positive regulator of Wnt/STOP signaling (Chen et al., 2018). These data suggest that LRP6 phosphorylation-mediated Wnt signaling can be transduced in a $\beta$-catenin-independent manner (Figure 5D).

\section{LRP6 DYSREGULATION AND DISEASE}

\section{Cancer}

Dysregulation of $\mathrm{Wnt} / \beta$-catenin signaling is highly associated with cancer, and mutations in AXIN, APC, and $\beta$-catenin often lead to increased cancer formation and metastasis (Bugter et al., 2021). Similarly, dysregulation of LRP6 is also involved in cancer. LRP6 is highly expressed in several cancer cell lines and overexpression of LRP6 promotes cancer cell proliferation ( $\mathrm{Li}$ et al., 2004). More specifically, LRP6 is a well-known regulator of breast cancer: LRP6 expression is frequently upregulated in breast cancer tissue, and respective overexpression or knockdown of LRP6 induces or inhibits breast tumorigenesis ( $\mathrm{Li}$ et al., 2004; Lindvall et al., 2009; Liu et al., 2010; Zhang et al., 2010). The role of LRP6 in breast cancer tumorigenesis is highly dependent on $\mathrm{Wnt} / \beta$-catenin signaling. If antibodies that block
LRP6-Wnt1 or LRP6-Wnt3a interactions are administered in mice, Wnt/ $\beta$-catenin signaling is blocked and breast tumor growth is suppressed (Ettenberg et al., 2010). In breast cancer tissue, high expression of the Sry-related HMG box 9 protein (SOX9) activates $\mathrm{Wnt} / \beta$-catenin signaling by inducing LRP6 expression (Wang et al., 2013). LRP6 also plays a role in breast cancer metastasis. N-myc downstream regulated gene-1 protein (NDRG1) interacts with LRP6 and suppresses LRP6mediated Wnt signaling activation, resulting in inhibition of breast cancer metastasis (Liu et al., 2012). Contrastingly, in the absence of Wnt3a, LRP6 inhibits FZD8-mediated noncanonical Wnt signaling by interacting with the extracellular domain of FZD8 (Ren et al., 2015). As a result, breast tumor metastasis, which is usually promoted by non-canonical Wnt signaling, is inhibited through the extracellular domain of LRP6 (Ren et al., 2015). Therefore, LRP6 seems to play a dual role in breast tumor metastasis that depends on the presence or absence of Wnt.

Another cancer with which LRP6 is highly correlated is liver cancer. LRP6 is highly expressed in tumors of liver cancer patients, and overexpression of LRP6 promotes liver cancer cell proliferation and tumor growth (Tung et al., 2012). Several components are involved in liver cancer progression via regulation of LRP6. For example, expression of stearoyl-CoA desaturase (SCD) is increased in liver tumors, where it promotes the production of monounsaturated fatty acids (MUFA) (Lai et al., 2017). MUFA induces expression of LRP6 and activation of $\mathrm{Wnt} / \beta$-catenin signaling, which then activates expression of $S C D$, functioning as a positive feedback loop (Lai et al., 2017). Connective tissue growth factor (CTGF) is highly expressed in liver cancer patients, and CTGF promotes phosphorylation of LRP6 (Jia et al., 2017). Finally, expression of long non-coding RNA DLGAP1-AS1 is increased in liver cancer tissue, where it inhibits miR-26a/b-5p, a negative regulator of LRP6 expression (Lin et al., 2020).

In colorectal cancer, elevated activity of LRP6 has been reported. LRP6 phosphorylation was also found to be enhanced in colorectal cancer tissue from patients (Lemieux et al., 2015). In colorectal cancer cells, gain of function mutations in KRAS increase LRP6 phosphorylation, resulting in activation of Wnt/ $\beta$-catenin signaling (Lemieux et al., 2015). CD110 receptor-expressing colorectal cancer tumor-initiating cells (TICs) are activated via thrombopoietin in blood vessels. In TICs, production of acetyl-CoA is promoted via degradation of lysine, and the LRP6 K802 residue is acetylated (Wu et al., 2015). Acetylation of LRP6 leads to its phosphorylation in a $\mathrm{CK} 1 \gamma$-dependent manner, leading to activation of Wnt $/ \beta$-catenin signaling. As a result, self-renewal and metastasis of colorectal cancer TICs are enhanced (Wu et al., 2015). V-set and transmembrane domain containing 2A (VSTM2A) is a secretory protein that is lowly expressed in colorectal cancer tissue (Dong et al., 2019). VSTM2A interacts with the extracellular domain of LRP6 and inhibits LRP6 phosphorylation, thereby inducing its lysosomal degradation, and suppressing colorectal cancer progression (Dong et al., 2019).

In addition to breast, liver, and colorectal cancer, the role of LRP6 in other cancers has been studied. In prostate cancer, high 
expression levels of caveolin-1 and LRP6 are detected, and these two proteins activate $\mathrm{Wnt} / \beta$-catenin signaling and glycolysis through Akt signaling. The end result is increased prostate cancer cell proliferation (Tahir et al., 2013). Through mass spectrometry-based proteomic analyses of mass spectrometry data, it was identified that LRP6 expression is high in oral squamous cell carcinoma (OSCC) (Yuan et al., 2017). In addition, LRP6 increases the protein levels of fibroblast growth factor 8 (FGF8), which can act as an oncogene and promote OSCC progression (Yuan et al., 2017). LRP6 is also involved in regulating the activity of cancer-associated fibroblasts (CAFs). In the stroma of breast, colon, and ovarian cancers, Dkk3 expression and internalization with Kremen $1 / 2$ are enhanced, resulting in upregulation of LRP6 protein levels (Ferrari et al., 2019). Finally, LRP6 stabilizes not only $\beta$-catenin, but also YAP/TAZ. Stabilized YAP/TAZ enters the nucleus where it enhances tumorigenic activity in various cancer types (Ferrari et al., 2019).

\section{Neurodegeneration}

Cognitive and behavioral disorders caused by functional neuron failure and neuronal death are referred to as neurodegeneration. Representative examples include Alzheimer's, Parkinson's, and Huntington's diseases. The causes of neurodegeneration include genetic mutations, protein aggregation, mitochondrial dysfunction, etc. However, the molecular mechanisms underlying neurodegeneration still require further elucidation (Gan et al., 2018). The relationship between Wnt signaling dysregulation and neurodegeneration has been reported, and several studies have shown that mutations in LRP6 are associated with neurodegeneration.

Through genome-wide screening, it was identified that a single nucleotide polymorphism (SNP) in the 1062 residue of LRP6, which converts isoleucine to valine (hereafter referred to as Ile1062Val), leads to reduced $\mathrm{Wnt} / \beta$-catenin signaling and is implicated in Alzheimer's disease (De Ferrari et al., 2007). In addition, it was also shown that an isoform that skips the third exon of LRP6 and displays reduced Wnt/ $\beta$-catenin signaling activation is significantly augmented in the brains of patients with Alzheimer's disease (Alarcón et al., 2013). When LRP6 is specifically deleted in the forebrain, synapse formation is suppressed while amyloid- $\beta$ accumulation and neuronal apoptosis are promoted, altogether resulting in aggravation of Alzheimer's disease symptoms (Liu et al., 2014). Consistently, in Alzheimer's disease patients, $D K K 1$ is highly expressed and causes suppression of LRP6-amyloid precursor protein (APP)mediated $\mathrm{Wnt} / \beta$-catenin signaling, which results in accumulation of amyloid- $\beta$ and synapse loss (Elliott et al., 2018). These data suggest that dysregulation of LRP6 function in the brain leads to suppression of $\mathrm{Wnt} / \beta$-catenin signaling and exacerbation of Alzheimer's disease symptoms. A positive role of LRP6 for neuronal activity has also been reported. Through genetic screening, LRP6 was found to localize to excitatory synapses of mature neurons and promote synaptogenesis (Sharma et al., 2013), and Wnt3a and Wnt8 have been shown to cooperate with LRP6 in this process (Avila et al., 2010; Sharma et al., 2013). Moreover, APP, also known as precursor of amyloid- $\beta$, interacts with LRP6 and activates Wnt/ $\beta$-catenin signaling, leading to enhanced synaptic stability (Elliott et al., 2018).

It is well-known that mutations in $P A R K 8$ are implicated in Parkinson's disease (Kumari and Tan, 2009). LRRK2, a product of PARK8 gene, interacts with LRP6 and acts as a scaffold between LRP6 and the $\beta$-catenin destruction complex (Berwick and Harvey, 2012). Pathogenic mutations in LRRK2 lead to reduced interaction with LRP6, suppressing Wnt/ $\beta$-catenin signaling (Berwick and Harvey, 2012).

LRP6 also plays a protective role in brain ischemic injury (Abe et al., 2013). Compared to wild-type mice, more areas of the brain are damaged through ischemic injury in LRP6 ${ }^{+/-}$mice. GSK3 $\beta$ activity and expression of inflammatory marker genes are also increased in the brains of $\mathrm{LRP}^{+/-}$mice (Abe et al., 2013).

\section{Metabolic Syndrome}

Metabolic syndrome is characterized by abnormal levels of metabolites (e.g., sugars and lipids) in the body and is highly associated with cardiovascular disease and diabetes. Risk factors for metabolic syndrome are diet, low physical activity, aging, and genetics (Rochlani et al., 2017). The relationship between LRP6 dysfunction and metabolic syndrome has been widely studied.

It is well known that dysregulation of LRP6 is highly associated with coronary artery disease (CAD) and atherosclerosis. Through genome-wide analysis of CAD patients, R473Q, R360H, N433S, and $\mathrm{R} 611 \mathrm{C}$ residue mutations in LRP6 were found to be correlated with CAD pathogenesis, as determined by high glucose, lipid, and low-density lipoprotein (LDL) levels in blood vessels (Mani et al., 2007; Singh et al., 2013b). In addition, the LRP6 R611C mutation, which does not effectively activate Wnt/ $\beta$-catenin signaling compared to wild-type LRP6, leads to low LDL uptake and clearance. Taken together, these data suggest that LRP6 is a critical modulator of receptor-mediated LDL endocytosis (Mani et al., 2007; Liu et al., 2008; Ye et al., 2012).

Abnormal proliferation of vascular smooth muscle cells (VSMC) via activation of PDGF signaling is a well-known cause of atherosclerosis (Raines, 2004). Wild-type LRP6 interacts with PDGF receptor- $\beta$ and causes its lysosomal degradation, a function that is impaired in the LRP6 R611C form (Keramati et al., 2011). As a result, VSMC proliferation through PDGF signaling is increased in $\mathrm{Lrp6}^{\mathrm{R} 611 \mathrm{C} / \mathrm{R} 611 \mathrm{C}}$ mutants (Keramati et al., 2011). Moreover, VSMCs from Lrp6 $6^{\mathrm{R} 611 \mathrm{C} / \mathrm{R} 611 \mathrm{C}}$ mice exhibit suppressed $\mathrm{Wnt} / \beta$-catenin signaling but increased noncanonical Wnt signaling, a shift that results in the activation of PDGF signaling via SP1 (Srivastava et al., 2015). Consequently, VSMCs are maintained in an undifferentiated form in the arterial wall, further increasing their proliferation and causing them to migrate at accelerated rates (Srivastava et al., 2015). In summary, impairment of LRP6 activity is highly correlated with CAD through PDGF signaling. Finally, the miRNA-17 92 cluster targets LRP6 and downregulates Wnt/ $\beta$-catenin signaling, and deficiency of miRNA-17 92 in endothelial cells improves blood flow and arteriogenesis (Landskroner-Eiger et al., 2015).

The LRP6 R611C mutant form is also associated with altered insulin signaling. R611C mutation of LRP6 in skeletal muscle suppresses TCF7L2-dependent transcription of the insulin receptor (IR) and reduces its protein levels. This results in low 
insulin sensitivity and high glucose level in blood vessels, both of which contribute to type II diabetes (Singh et al., 2013a).

Additionally, Lrp6 ${ }^{\mathrm{R} 611 \mathrm{C} / \mathrm{R} 611 \mathrm{C}}$ mice maintain a high level of LDL and lipids in the plasma, which induces fatty liver (Go et al., 2014). In Lrp6 ${ }^{\mathrm{R} 611 \mathrm{C} / \mathrm{R} 611 \mathrm{C}}$ mutant hepatocytes, IGF/Akt/mTORC1/2 signaling and lipid synthesis are activated, and treatment with the mTOR inhibitor rapamycin or recombinant $\mathrm{Wnt} 3 \mathrm{a}$ rescue these pathogenic effects (Go et al., 2014).

Cardiac-specific knockout of LRP6 activates dynaminrelated protein 1 (Drp1) in heart tissue and reduces carnitine palmitoyltransferase 1b (CPT1b) (Wang et al., 2020). Since CPT1b is an enzyme involved in lipid oxidation, downregulation of CPT1b levels due to LRP6 deficiency causes lipid accumulation in heart tissue and reduces left ventricular ejection fraction (LVEF), altogether leading to cardiac dysfunction (Wang et al., 2020).

\section{Inflammation}

Organ homeostasis is maintained through the coordinated action of inflammatory cytokines with host defense function, and dysregulation of inflammatory cytokines is implicated in immune disease or cancer (Greten and Grivennikov, 2019). Moreover, inflammatory cytokines can regulate Wnt/LRP6 signaling. For instance, long exposure to pro-inflammatory cytokine interferon$\gamma$ or TNF- $\alpha$ induces Dkk1 expression and inhibits $W n t / \beta$-catenin signaling, leading to increased intestinal inflammation (Nava et al., 2010). Ileal Crohn's disease (CD) is a disease that causes pain, diarrhea, and malnutrition due to chronic inflammation in the intestine (Koslowski et al., 2012). Genome-wide analysis from CD patients revealed an association between the Ile1062Val LRP6 SNP with early disease onset. Lower levels of LRP6 mRNA were also detected in these patient samples (Koslowski et al., 2012). Dendritic cell (DC)-specific knockout of LRP5/6 promotes differentiation of effector $\mathrm{T}$ cells and represses regulatory $\mathrm{T}$ cell differentiation, resulting in enhanced anti-tumor immunity and inhibition of tumor growth, both of which show that fine regulation of LRP6 is essential for proper immune responses (Hong et al., 2016).

\section{Skeletal Disease}

Bone mass formation and maintenance is regulated by the activity of osteoblasts, which form bone, and osteoclasts, which degrade bone. Dysregulation of bone mass leads to osteoporosis or sclerosteosis, diseases that are heavily influenced by genetic factors (Regard et al., 2012). For instance, LRP5 mutations generally lead to decreased bone mass and osteoporosis due to reduced Wnt/ $\beta$-catenin signaling (Gong et al., 2001). One exception is the G171V mutation in LRP5, which increases rather than decreases bone mass (Babij et al., 2003). LRP6 is a paralog of LRP5, and studies on the association between LRP6 and bone homeostasis have also been performed. For example, heterozygous deficiency of LRP6 in mice leads to a reduction in bone mineral density (BMD) (Holmen et al., 2004). Moreover, combination of LRP6 heterozygous deficiency with LRP5 homozygous deficiency, leads to a greater reduction in BMD compared to LRP5 homozygous deficiency alone
(Holmen et al., 2004). Tissue-specific ablation of LRP5 and LRP6 in the mesenchyme, which is the precursor of skeletal tissue, leads to embryonic skeletal defects, similar to the phenotype seen upon mesenchyme-specific deletion of $\beta$-catenin (Joeng et al., 2011).

Several proteins that bind to LRP6 regulate bone formation via modulation of $\mathrm{Wnt} / \beta$-catenin signaling. It is well-known that loss-of-functions mutation in sclerostin (expressed by the SOST gene) cause sclerosteosis (Balemans et al., 2001). Sclerostin inhibits $\mathrm{Wnt} / \beta$-catenin signaling by binding to LRP6 and disrupting FZD-LRP6 interaction (Li et al., 2005; Semënov et al., 2005). Biglycan, a type of proteoglycan, activates Wnt/ $\beta$-catenin signaling by maintaining the interaction between $\mathrm{Wnt} 3 \mathrm{a}$ and LRP6, and deficiency of biglycan compromises bone formation (Berendsen et al., 2011).

Parathyroid hormone interacts with PTH1R to promote LRP6 phosphorylation and activate $\mathrm{Wnt} / \beta$-catenin signaling in osteoblasts, leading to increased bone formation (Wan et al., 2008). Osteoblast-specific knockout of LRP6 reduces the expression of osteoblast differentiation-related genes and suppresses bone formation, even in the presence of PTH (Li et al., 2013, 2016).

Oxidized phospholipids bind to LRP6 and reduce LRP6 plasma membrane levels via clathrin-dependent endocytosis (Wang et al., 2018). As a result, phosphorylation of LRP6 and $\mathrm{Wnt} / \beta$-catenin signaling are reduced, inhibiting osteoblast differentiation (Wang et al., 2018). It has also been shown that oxidized phospholipid levels are high in patients suffering from hyperlipidemia, suggesting that LRP6 may have an important role in the occurrence of osteoporosis via hyperlipidemia (Wang et al., 2018).

\section{PERSPECTIVES (CLOSING REMARKS)}

It has been more than 20 years since LRP6 was discovered as a co-receptor for Wnt/ $\beta$-catenin signaling. Most studies focusing on the mechanisms underlying LRP6-mediated Wnt/ $\beta$-catenin signaling have concentrated on phosphorylation events in the intracellular domain of LRP6. However, recent reports have determined that additional PTMs such as ubiquitination, acetylation, and $O$-GlcNAcylation are also essential for regulating LRP6 activity. Moreover, LRP6 is involved in multiple signaling cascades apart from Wnt/ $\beta$-catenin. These include, but are not limited to, non-canonical Wnt signaling, GPCR signaling, cell cycle-related signaling, and Hippo signaling (Figure 5). Until now, the occurrence of disease via dysregulation of LRP6 has been primarily linked to aberrant Wnt/ $\beta$-catenin signaling. However, we suggest that future studies focusing on LRP6 and disease should also investigate the involvement of other signaling pathways. Moreover, since single point mutations in LRP6 are linked to multiple diseases, it would be worthwhile to analyze the cross-talk between these diseases, and to more thoroughly decipher their connections to LRP6. Considering the complex mechanisms surrounding the regulation and activation of LRP6, as well as its important role in disease occurrence, LRP6 is thus expected to be an attractive therapeutic target in future studies. 


\section{AUTHOR CONTRIBUTIONS}

WJ planned and wrote the manuscript. EJ directed, edited, and finalized the manuscript. Both authors read and approved the final version of the manuscript.

\section{REFERENCES}

Abe, T., Zhou, P., Jackman, K., Capone, C., Casolla, B., Hochrainer, K., et al. (2013). Lipoprotein receptor-related protein- 6 protects the brain from ischemic injury. Stroke 44, 2284-2291. doi: 10.1161/strokeaha.113.001320

Aberle, H., Bauer, A., Stappert, J., Kispert, A., and Kemler, R. (1997). Beta-catenin is a target for the ubiquitin-proteasome pathway. EMBO J. 16, 3797-3804. doi: $10.1093 / \mathrm{emboj} / 16.13 .3797$

Abrami, L., Kunz, B., Iacovache, I., and van der Goot, F. G. (2008). Palmitoylation and ubiquitination regulate exit of the Wnt signaling protein LRP6 from the endoplasmic reticulum. Proc. Natl. Acad. Sci. U.S.A. 105, 5384-5389. doi: 10. 1073/pnas.0710389105

Acebron, S. P., and Niehrs, C. (2016). $\beta$-catenin-independent roles of Wnt/LRP6 signaling. Trends Cell Biol. 26, 956-967. doi: 10.1016/j.tcb.2016.07.009

Acebron, S. P., Karaulanov, E., Berger, B. S., Huang, Y. L., and Niehrs, C. (2014). Mitotic wnt signaling promotes protein stabilization and regulates cell size. Mol. Cell 54, 663-674. doi: 10.1016/j.molcel.2014.04.014

Agajanian, M. J., Walker, M. P., Axtman, A. D., Ruela-de-Sousa, R. R., Serafin, D. S., Rabinowitz, A. D., et al. (2019). WNT activates the AAK1 kinase to promote clathrin-mediated endocytosis of LRP6 and establish a negative feedback loop. Cell Rep. 26, 79-93.e8. doi: 10.1016/j.celrep.2018.12.023

Alarcón, M. A., Medina, M. A., Hu, Q., Avila, M. E., Bustos, B. I., Pérez-Palma, E., et al. (2013). A novel functional low-density lipoprotein receptor-related protein 6 gene alternative splice variant is associated with Alzheimer's disease. Neurobiol. Aging 34, e1709-e1718. doi: 10.1016/j.neurobiolaging.2012.11.004

Avila, M. E., Sepúlveda, F. J., Burgos, C. F., Moraga-Cid, G., Parodi, J., Moon, R. T., et al. (2010). Canonical Wnt3a modulates intracellular calcium and enhances excitatory neurotransmission in hippocampal neurons. J. Biol. Chem. 285, 18939-18947. doi: 10.1074/jbc.M110.103028

Azzolin, L., Panciera, T., Soligo, S., Enzo, E., Bicciato, S., Dupont, S., et al. (2014). YAP/TAZ incorporation in the beta-catenin destruction complex orchestrates the Wnt response. Cell 158, 157-170. doi: 10.1016/j.cell.2014.06.013

Babij, P., Zhao, W., Small, C., Kharode, Y., Yaworsky, P. J., Bouxsein, M. L., et al. (2003). High bone mass in mice expressing a mutant LRP5 gene. J. Bone Miner. Res. 18, 960-974. doi: 10.1359/jbmr.2003.18.6.960

Bafico, A., Liu, G., Yaniv, A., Gazit, A., and Aaronson, S. A. (2001). Novel mechanism of Wnt signalling inhibition mediated by Dickkopf-1 interaction with LRP6/Arrow. Nat. Cell Biol. 3, 683-686. doi: 10.1038/35083081

Balemans, W., Ebeling, M., Patel, N., Van Hul, E., Olson, P., Dioszegi, M., et al. (2001). Increased bone density in sclerosteosis is due to the deficiency of a novel secreted protein (SOST). Hum. Mol. Genet. 10, 537-543. doi: 10.1093/hmg/10. 5.537

Berendsen, A. D., Fisher, L. W., Kilts, T. M., Owens, R. T., Robey, P. G., Gutkind, J. S., et al. (2011). Modulation of canonical Wnt signaling by the extracellular matrix component biglycan. Proc. Natl. Acad. Sci. U.S.A. 108, 17022-17027. doi: 10.1073/pnas.1110629108

Berger, B. S., Acebron, S. P., Herbst, J., Koch, S., and Niehrs, C. (2017). Parkinson's disease-associated receptor GPR37 is an ER chaperone for LRP6. EMBO Rep. 18, 712-725. doi: 10.15252/embr.201643585

Berwick, D. C., and Harvey, K. (2012). LRRK2 functions as a Wnt signaling scaffold, bridging cytosolic proteins and membrane-localized LRP6. Hum. Mol. Genet. 21, 4966-4979. doi: 10.1093/hmg/dds342

Bilic, J., Huang, Y. L., Davidson, G., Zimmermann, T., Cruciat, C. M., Bienz, M., et al. (2007). Wnt induces LRP6 signalosomes and promotes dishevelleddependent LRP6 phosphorylation. Science 316, 1619-1622. doi: 10.1126/ science. 1137065

Bryja, V., Andersson, E. R., Schambony, A., Esner, M., Bryjová, L., Biris, K. K., et al. (2009). The extracellular domain of Lrp5/6 inhibits noncanonical Wnt signaling in vivo. Mol. Biol. Cell 20, 924-936. doi: 10.1091/mbc.e08-07-0711

\section{FUNDING}

This study was supported by the National Research Foundation of Korea (NRF-2020R1A2C3013746 and 2017M3A9B4062421 to EJ).

Bugter, J. M., Fenderico, N., and Maurice, M. M. (2021). Mutations and mechanisms of WNT pathway tumour suppressors in cancer. Nat. Rev. Cancer 21, 5-21. doi: 10.1038/s41568-020-00307-z

Carmon, K. S., Gong, X., Lin, Q., Thomas, A., and Liu, Q. (2011). R-spondins function as ligands of the orphan receptors LGR4 and LGR5 to regulate Wnt/beta-catenin signaling. Proc. Natl. Acad. Sci. U.S.A. 108, 11452-11457. doi: 10.1073/pnas.1106083108

Červenka, I., Wolf, J., Mašek, J., Krejci, P., Wilcox, W. R., Kozubík, A., et al. (2011). Mitogen-activated protein kinases promote WNT/beta-catenin signaling via phosphorylation of LRP6. Mol. Cell. Biol. 31, 179-189. doi: 10.1128/mcb. 00550-10

Chen, J., Rajasekaran, M., Xia, H., Kong, S. N., Deivasigamani, A., Sekar, K., et al. (2018). CDK1-mediated BCL9 phosphorylation inhibits clathrin to promote mitotic Wnt signalling. EMBO J. 37:e99395. doi: 10.15252/embj.201899395

Chen, M., Philipp, M., Wang, J., Premont, R. T., Garrison, T. R., Caron, M. G., et al. (2009). G Protein-coupled receptor kinases phosphorylate LRP6 in the Wnt pathway. J. Biol. Chem. 284, 35040-35048. doi: 10.1074/jbc.M109.047456

Chen, Q., Su, Y., Wesslowski, J., Hagemann, A. I., Ramialison, M., Wittbrodt, J., et al. (2014). Tyrosine phosphorylation of LRP6 by Src and Fer inhibits Wnt/ $\beta$ catenin signalling. EMBO Rep. 15, 1254-1267. doi: 10.15252/embr.201439644

Cheng, Z., Biechele, T., Wei, Z., Morrone, S., Moon, R. T., Wang, L., et al. (2011). Crystal structures of the extracellular domain of LRP6 and its complex with DKK1. Nat. Struct. Mol. Biol. 18, 1204-1210. doi: 10.1038/nsmb.2139

Colozza, G., Jami-Alahmadi, Y., Dsouza, A., Tejeda-Muñoz, N., Albrecht, L. V., Sosa, E. A., et al. (2020). Wnt-inducible Lrp6-APEX2 interacting proteins identify ESCRT machinery and Trk-fused gene as components of the Wnt signaling pathway. Sci. Rep. 10:21555. doi: 10.1038/s41598-020-78019-5

Cselenyi, C. S., Jernigan, K. K., Tahinci, E., Thorne, C. A., Lee, L. A., and Lee, E. (2008). LRP6 transduces a canonical Wnt signal independently of Axin degradation by inhibiting GSK3's phosphorylation of beta-catenin. Proc. Natl. Acad. Sci. U.S.A. 105, 8032-8037. doi: 10.1073/pnas.0803025105

Davidson, G., Shen, J., Huang, Y. L., Su, Y., Karaulanov, E., Bartscherer, K., et al. (2009). Cell cycle control of wnt receptor activation. Dev. Cell 17, 788-799. doi: 10.1016/j.devcel.2009.11.006

Davidson, G., Wu, W., Shen, J., Bilic, J., Fenger, U., Stannek, P., et al. (2005). Casein kinase 1 gamma couples Wnt receptor activation to cytoplasmic signal transduction. Nature 438, 867-872. doi: 10.1038/nature04170

De Ferrari, G. V., Papassotiropoulos, A., Biechele, T., Wavrant De-Vrieze, F., Avila, M. E., Major, M. B., et al. (2007). Common genetic variation within the low-density lipoprotein receptor-related protein 6 and late-onset Alzheimer's disease. Proc. Natl. Acad. Sci. U.S.A. 104, 9434-9439. doi: 10.1073/pnas. 0603523104

Demir, K., Kirsch, N., Beretta, C. A., Erdmann, G., Ingelfinger, D., Moro, E., et al. (2013). RAB8B is required for activity and caveolar endocytosis of LRP6. Cell Rep. 4, 1224-1234. doi: 10.1016/j.celrep.2013.08.008

Ding, Y., Colozza, G., Sosa, E. A., Moriyama, Y., Rundle, S., Salwinski, L., et al. (2018). Bighead is a Wnt antagonist secreted by the Xenopus Spemann organizer that promotes Lrp6 endocytosis. Proc. Natl. Acad. Sci. U.S.A. 115, E9135-E9144. doi: $10.1073 /$ pnas. 1812117115

Dong, Y., Zhang, Y., Kang, W., Wang, G., Chen, H., Higashimori, A., et al. (2019). VSTM2A suppresses colorectal cancer and antagonizes Wnt signaling receptor LRP6. Theranostics 9, 6517-6531. doi: 10.7150/thno.34989

Elliott, C., Rojo, A. I., Ribe, E., Broadstock, M., Xia, W., Morin, P., et al. (2018). A role for APP in Wnt signalling links synapse loss with $\beta$-amyloid production. Transl. Psychiatry 8:179. doi: 10.1038/s41398-018-0231-6

Ettenberg, S. A., Charlat, O., Daley, M. P., Liu, S., Vincent, K. J., Stuart, D. D., et al. (2010). Inhibition of tumorigenesis driven by different Wnt proteins requires blockade of distinct ligand-binding regions by LRP6 antibodies. Proc. Natl. Acad. Sci. U.S.A. 107, 15473-15478. doi: 10.1073/pnas. 1007428107 
Ferrari, N., Ranftl, R., Chicherova, I., Slaven, N. D., Moeendarbary, E., Farrugia, A. J., et al. (2019). Dickkopf-3 links HSF1 and YAP/TAZ signalling to control aggressive behaviours in cancer-associated fibroblasts. Nat. Commun. 10:130. doi: 10.1038/s41467-018-07987-0

Gan, L., Cookson, M. R., Petrucelli, L., and La Spada, A. R. (2018). Converging pathways in neurodegeneration, from genetics to mechanisms. Nat. Neurosci. 21, 1300-1309. doi: 10.1038/s41593-018-0237-7

Go, G. W., Srivastava, R., Hernandez-Ono, A., Gang, G., Smith, S. B., Booth, C. J., et al. (2014). The combined hyperlipidemia caused by impaired WntLRP6 signaling is reversed by Wnt3a rescue. Cell Metab. 19, 209-220. doi: 10.1016/j.cmet.2013.11.023

Gong, Y., Slee, R. B., Fukai, N., Rawadi, G., Roman-Roman, S., Reginato, A. M., et al. (2001). LDL receptor-related protein 5 (LRP5) affects bone accrual and eye development. Cell 107, 513-523. doi: 10.1016/s0092-8674(01)00571-2

Greten, F. R., and Grivennikov, S. I. (2019). Inflammation and cancer: triggers, mechanisms, and consequences. Immunity 51, 27-41. doi: 10.1016/j.immuni. 2019.06.025

Grumolato, L., Liu, G., Mong, P., Mudbhary, R., Biswas, R., Arroyave, R., et al. (2010). Canonical and noncanonical Wnts use a common mechanism to activate completely unrelated coreceptors. Genes Dev. 24, 2517-2530. doi: 10. 1101/gad.1957710

Hao, H. X., Xie, Y., Zhang, Y., Charlat, O., Oster, E., Avello, M., et al. (2012). ZNRF3 promotes Wnt receptor turnover in an R-spondin-sensitive manner. Nature 485, 195-200. doi: 10.1038/nature11019

Holmen, S. L., Giambernardi, T. A., Zylstra, C. R., Buckner-Berghuis, B. D., Resau, J. H., Hess, J. F., et al. (2004). Decreased BMD and limb deformities in mice carrying mutations in both Lrp5 and Lrp6. J. Bone Miner. Res. 19, 2033-2040. doi: 10.1359/jbmr.040907

Hong, S., Feng, L., Yang, Y., Jiang, H., Hou, X., Guo, P., et al. (2020). In situ fucosylation of the Wnt co-receptor LRP6 increases its endocytosis and reduces Wnt/ $\beta$-catenin signaling. Cell Chem. Biol. 27, 1140-1150.e4. doi: 10.1016/j. chembiol.2020.06.015

Hong, Y., Manoharan, I., Suryawanshi, A., Shanmugam, A., Swafford, D., Ahmad, S., et al. (2016). Deletion of LRP5 and LRP6 in dendritic cells enhances antitumor immunity. Oncoimmunology 5:e1115941. doi: 10.1080/2162402x. 2015.1115941

Hsieh, J. C., Lee, L., Zhang, L., Wefer, S., Brown, K., DeRossi, C., et al. (2003). Mesd encodes an LRP5/6 chaperone essential for specification of mouse embryonic polarity. Cell 112, 355-367. doi: 10.1016/s0092-8674(03)00045-x

Jeong, W., Kim, S., Lee, U., Zhong, Z. A., Savitsky, M., Kwon, H., et al. (2020). LDL receptor-related protein LRP6 senses nutrient levels and regulates Hippo signaling. EMBO Rep. 21:e50103. doi: 10.15252/embr.202050103

Jernigan, K. K., Cselenyi, C. S., Thorne, C. A., Hanson, A. J., Tahinci, E., Hajicek, N., et al. (2010). Gbetagamma activates GSK3 to promote LRP6-mediated beta-catenin transcriptional activity. Sci. Signal. 3:ra37. doi: 10.1126/scisignal. 2000647

Jia, Q., Bu, Y., Wang, Z., Chen, B., Zhang, Q., Yu, S., et al. (2017). Maintenance of stemness is associated with the interation of LRP6 and heparin-binding protein CCN2 autocrined by hepatocellular carcinoma. J. Exp. Clin. Cancer Res. 36:117. doi: 10.1186/s13046-017-0576-3

Jiang, X., Charlat, O., Zamponi, R., Yang, Y., and Cong, F. (2015). Dishevelled promotes Wnt receptor degradation through recruitment of ZNRF3/RNF43 E3 ubiquitin ligases. Mol. Cell 58, 522-533. doi: 10.1016/j.molcel.2015.03.015

Jiang, Y., He, X., and Howe, P. H. (2012). Disabled-2 (Dab2) inhibits Wnt/ $\beta$ catenin signalling by binding LRP6 and promoting its internalization through clathrin. EMBO J. 31, 2336-2349. doi: 10.1038/emboj.2012.83

Joeng, K. S., Schumacher, C. A., Zylstra-Diegel, C. R., Long, F., and Williams, B. O. (2011). Lrp5 and Lrp6 redundantly control skeletal development in the mouse embryo. Dev. Biol. 359, 222-229. doi: 10.1016/j.ydbio.2011.08.020

Joiner, D. M., Ke, J., Zhong, Z., Xu, H. E., and Williams, B. O. (2013). LRP5 and LRP6 in development and disease. Trends Endocrinol. Metab. 24, 31-39. doi: 10.1016/j.tem.2012.10.003

Jung, H., Lee, S. K., and Jho, E. H. (2011). Mest/Peg1 inhibits Wnt signalling through regulation of LRP6 glycosylation. Biochem. J. 436, 263-269. doi: 10 . 1042/bj20101512

Kagermeier-Schenk, B., Wehner, D., Ozhan-Kizil, G., Yamamoto, H., Li, J., Kirchner, K., et al. (2011). Waif1/5T4 inhibits Wnt/ $\beta$-catenin signaling and activates noncanonical Wnt pathways by modifying LRP6 subcellular localization. Dev. Cell 21, 1129-1143. doi: 10.1016/j.devcel.2011.10.015

Keramati, A. R., Singh, R., Lin, A., Faramarzi, S., Ye, Z. J., Mane, S., et al. (2011). Wild-type LRP6 inhibits, whereas atherosclerosis-linked LRP6R611C increases PDGF-dependent vascular smooth muscle cell proliferation. Proc. Natl. Acad. Sci. U.S.A. 108, 1914-1918. doi: 10.1073/pnas.1019443108

Khan, Z., Vijayakumar, S., de la Torre, T. V., Rotolo, S., and Bafico, A. (2007). Analysis of endogenous LRP6 function reveals a novel feedback mechanism by which Wnt negatively regulates its receptor. Mol. Cell. Biol. 27, 7291-7301. doi: $10.1128 / \mathrm{mcb} .00773-07$

Kikuchi, A., Yamamoto, H., and Sato, A. (2009). Selective activation mechanisms of Wnt signaling pathways. Trends Cell Biol. 19, 119-129. doi: 10.1016/j.tcb.2009. 01.003

Kim, I., Pan, W., Jones, S. A., Zhang, Y., Zhuang, X., and Wu, D. (2013). Clathrin and AP2 are required for PtdIns(4,5)P2-mediated formation of LRP6 signalosomes. J. Cell Biol. 200, 419-428. doi: 10.1083/jcb.201206096

Kim, M., Kim, S., Lee, S. H., Kim, W., Sohn, M. J., Kim, H. S., et al. (2016). Merlin inhibits Wnt/ $\beta$-catenin signaling by blocking LRP6 phosphorylation. Cell Death Differ. 23, 1638-1647. doi: 10.1038/cdd.2016.54

Kim, W., Kim, S. Y., Kim, T., Kim, M., Bae, D. J., Choi, H. I., et al. (2013). ADPribosylation factors 1 and 6 regulate Wnt/ $\beta$-catenin signaling via control of LRP6 phosphorylation. Oncogene 32, 3390-3396. doi: 10.1038/onc.2012.373

Kirsch, N., Chang, L. S., Koch, S., Glinka, A., Dolde, C., Colozza, G., et al. (2017). Angiopoietin-like 4 Is a Wnt Signaling Antagonist that Promotes LRP6 Turnover. Dev. Cell 43, 71.e-82.e. doi: 10.1016/j.devcel.2017.09.011

Kitagawa, M., Hatakeyama, S., Shirane, M., Matsumoto, M., Ishida, N., Hattori, K., et al. (1999). An F-box protein, FWD1, mediates ubiquitin-dependent proteolysis of beta-catenin. $E M B O J .18,2401-2410$. doi: 10.1093/emboj/18.9. 2401

Koo, B. K., Spit, M., Jordens, I., Low, T. Y., Stange, D. E., van de Wetering, M., et al. (2012). Tumour suppressor RNF43 is a stem-cell E3 ligase that induces endocytosis of Wnt receptors. Nature 488, 665-669. doi: 10.1038/nature11308

Koslowski, M. J., Teltschik, Z., Beisner, J., Schaeffeler, E., Wang, G., Kübler, I., et al. (2012). Association of a functional variant in the Wnt co-receptor LRP6 with early onset ileal Crohn's disease. PLoS Genet. 8:e1002523. doi: 10.1371/journal. pgen. 1002523

Krejci, P., Aklian, A., Kaucka, M., Sevcikova, E., Prochazkova, J., Masek, J. K., et al. (2012). Receptor tyrosine kinases activate canonical WNT/ $\beta$-catenin signaling via MAP kinase/LRP6 pathway and direct $\beta$-catenin phosphorylation. PLoS One 7:e35826. doi: 10.1371/journal.pone.0035826

Kumari, U., and Tan, E. K. (2009). LRRK2 in Parkinson's disease: genetic and clinical studies from patients. FEBS J. 276, 6455-6463. doi: 10.1111/j.1742-4658. 2009.07344.x

Lai, K. K. Y., Kweon, S. M., Chi, F., Hwang, E., Kabe, Y., Higashiyama, R., et al. (2017). Stearoyl-CoA desaturase promotes liver fibrosis and tumor development in mice via a Wnt positive-signaling loop by stabilization of lowdensity lipoprotein-receptor-related proteins 5 and 6. Gastroenterology 152, 1477-1491. doi: 10.1053/j.gastro.2017.01.021

Landskroner-Eiger, S., Qiu, C., Perrotta, P., Siragusa, M., Lee, M. Y., Ulrich, V., et al. (2015). Endothelial miR-17 $\sim 92$ cluster negatively regulates arteriogenesis via miRNA-19 repression of WNT signaling. Proc. Natl. Acad. Sci. U.S.A. 112, 12812-12817. doi: 10.1073/pnas.1507094112

Lemieux, E., Cagnol, S., Beaudry, K., Carrier, J., and Rivard, N. (2015). Oncogenic KRAS signalling promotes the Wnt/ $\beta$-catenin pathway through LRP6 in colorectal cancer. Oncogene 34, 4914-4927. doi: 10.1038/onc.2014.416

Li, C., Wang, W., Xie, L., Luo, X., Cao, X., and Wan, M. (2016). Lipoprotein receptor-related protein 6 is required for parathyroid hormone-induced Sost suppression. Ann. N. Y. Acad. Sci. 1364, 62-73. doi: 10.1111/nyas. 12750

Li, C., Xing, Q., Yu, B., Xie, H., Wang, W., Shi, C., et al. (2013). Disruption of LRP6 in osteoblasts blunts the bone anabolic activity of PTH. J. Bone Miner. Res. 28, 2094-2108. doi: 10.1002/jbmr.1962

Li, X., Zhang, Y., Kang, H., Liu, W., Liu, P., Zhang, J., et al. (2005). Sclerostin binds to LRP5/6 and antagonizes canonical Wnt signaling. J. Biol. Chem. 280, 19883-19887. doi: 10.1074/jbc.M413274200

Li, Y., Lu, W., He, X., Schwartz, A. L., and Bu, G. (2004). LRP6 expression promotes cancer cell proliferation and tumorigenesis by altering beta-catenin subcellular distribution. Oncogene 23, 9129-9135. doi: 10.1038/sj.onc.1208123 
Lian, G., Dettenhofer, M., Lu, J., Downing, M., Chenn, A., Wong, T., et al. (2016). Filamin A- and formin 2-dependent endocytosis regulates proliferation via the canonical Wnt pathway. Development 143, 4509-4520. doi: 10.1242/dev. 139295

Liang, J., Fu, Y., Cruciat, C. M., Jia, S., Wang, Y., Tong, Z., et al. (2011). Transmembrane protein 198 promotes LRP6 phosphorylation and Wnt signaling activation. Mol. Cell. Biol. 31, 2577-2590. doi: 10.1128/mcb.05103-11

Lin, Y., Jian, Z., Jin, H., Wei, X., Zou, X., Guan, R., et al. (2020). Long non-coding RNA DLGAP1-AS1 facilitates tumorigenesis and epithelial-mesenchymal transition in hepatocellular carcinoma via the feedback loop of miR-26a/b5p/IL-6/JAK2/STAT3 and Wnt/ $\beta$-catenin pathway. Cell Death Dis. 11:34. doi: 10.1038/s41419-019-2188-7

Lindvall, C., Zylstra, C. R., Evans, N., West, R. A., Dykema, K., Furge, K. A., et al. (2009). The Wnt co-receptor Lrp6 is required for normal mouse mammary gland development. PLoS One 4:e5813. doi: 10.1371/journal.pone.0005813

Liu, B., Staron, M., Hong, F., Wu, B. X., Sun, S., Morales, C., et al. (2013). Essential roles of grp94 in gut homeostasis via chaperoning canonical Wnt pathway. Proc. Natl. Acad. Sci. U.S.A. 110, 6877-6882. doi: 10.1073/pnas.1302933110

Liu, C. C., Prior, J., Piwnica-Worms, D., and Bu, G. (2010). LRP6 overexpression defines a class of breast cancer subtype and is a target for therapy. Proc. Natl. Acad. Sci. U.S.A. 107, 5136-5141. doi: 10.1073/pnas.0911220107

Liu, C. C., Tsai, C. W., Deak, F., Rogers, J., Penuliar, M., Sung, Y. M., et al. (2014). Deficiency in LRP6-mediated Wnt signaling contributes to synaptic abnormalities and amyloid pathology in Alzheimer's disease. Neuron 84, 63-77. doi: 10.1016/j.neuron.2014.08.048

Liu, C., Li, Y., Semenov, M., Han, C., Baeg, G. H., Tan, Y., et al. (2002). Control of beta-catenin phosphorylation/degradation by a dual-kinase mechanism. Cell 108, 837-847. doi: 10.1016/s0092-8674(02)00685-2

Liu, G., Bafico, A., Harris, V. K., and Aaronson, S. A. (2003). A novel mechanism for Wnt activation of canonical signaling through the LRP6 receptor. Mol. Cell. Biol. 23, 5825-5835. doi: 10.1128/mcb.23.16.5825-5835.2003

Liu, W., Mani, S., Davis, N. R., Sarrafzadegan, N., Kavathas, P. B., and Mani, A. (2008). Mutation in EGFP domain of LDL receptor-related protein 6 impairs cellular LDL clearance. Circ. Res. 103, 1280-1288. doi: 10.1161/circresaha.108. 183863

Liu, W., Xing, F., Iiizumi-Gairani, M., Okuda, H., Watabe, M., Pai, S. K., et al. (2012). N-myc downstream regulated gene 1 modulates Wnt- $\beta$-catenin signalling and pleiotropically suppresses metastasis. EMBO Mol. Med. 4, 93108. doi: 10.1002/emmm.201100190

Lu, H., Ma, J., Yang, Y., Shi, W., and Luo, L. (2013). EpCAM is an endodermspecific Wnt derepressor that licenses hepatic development. Dev. Cell 24, 543-553. doi: 10.1016/j.devcel.2013.01.021

MacDonald, B. T., and He, X. (2012). Frizzled and LRP5/6 receptors for Wnt/ $\beta$ catenin signaling. Cold Spring Harb. Perspect. Biol. 4:a007880. doi: 10.1101/ cshperspect.a007880

MacDonald, B. T., Tamai, K., and He, X. (2009). Wnt/beta-catenin signaling: components, mechanisms, and diseases. Dev. Cell 17, 9-26. doi: 10.1016/j. devcel.2009.06.016

Madan, B., Walker, M. P., Young, R., Quick, L., Orgel, K. A., Ryan, M., et al. (2016). USP6 oncogene promotes Wnt signaling by deubiquitylating Frizzleds. Proc. Natl. Acad. Sci. U.S.A. 113, E2945-E2954. doi: 10.1073/pnas.160569 1113

Mani, A., Radhakrishnan, J., Wang, H., Mani, A., Mani, M. A., Nelson-Williams, C., et al. (2007). LRP6 mutation in a family with early coronary disease and metabolic risk factors. Science 315, 1278-1282. doi: 10.1126/science.1136370

Mao, B., Wu, W., Davidson, G., Marhold, J., Li, M., Mechler, B. M., et al. (2002). Kremen proteins are Dickkopf receptors that regulate Wnt/beta-catenin signalling. Nature 417, 664-667. doi: 10.1038/nature756

Mao, B., Wu, W., Li, Y., Hoppe, D., Stannek, P., Glinka, A., et al. (2001). LDLreceptor-related protein 6 is a receptor for Dickkopf proteins. Nature 411, 321-325. doi: 10.1038/35077108

Mao, J., Wang, J., Liu, B., Pan, W., Farr, G. H. III, Flynn, C., et al. (2001). Lowdensity lipoprotein receptor-related protein-5 binds to Axin and regulates the canonical Wnt signaling pathway. Mol. Cell 7, 801-809. doi: 10.1016/s10972765(01)00224-6

Meng, Z., Moroishi, T., and Guan, K. L. (2016). Mechanisms of Hippo pathway regulation. Genes Dev. 30, 1-17. doi: 10.1101/gad.274027.115
Metcalfe, C., Mendoza-Topaz, C., Mieszczanek, J., and Bienz, M. (2010). Stability elements in the LRP6 cytoplasmic tail confer efficient signalling upon DIXdependent polymerization. J. Cell Sci. 123(Pt 9), 1588-1599. doi: 10.1242/jcs. 067546

Nava, P., Koch, S., Laukoetter, M. G., Lee, W. Y., Kolegraff, K., Capaldo, C. T., et al. (2010). Interferon-gamma regulates intestinal epithelial homeostasis through converging beta-catenin signaling pathways. Immunity 32, 392-402. doi: 10. 1016/j.immuni.2010.03.001

Nusse, R., and Clevers, H. (2017). Wnt/ $\beta$-catenin signaling, disease, and emerging therapeutic modalities. Cell 169, 985-999. doi: 10.1016/j.cell.2017.05.016

Özhan, G., Sezgin, E., Wehner, D., Pfister, A. S., Kühl, S. J., Kagermeier-Schenk, B., et al. (2013). Lypd6 enhances Wnt/ $\beta$-catenin signaling by promoting Lrp6 phosphorylation in raft plasma membrane domains. Dev. Cell 26, 331-345. doi: 10.1016/j.devcel.2013.07.020

Pan, D. (2010). The hippo signaling pathway in development and cancer. Dev. Cell 19, 491-505. doi: 10.1016/j.devcel.2010.09.011

Pan, W., Choi, S. C., Wang, H., Qin, Y., Volpicelli-Daley, L., Swan, L., et al. (2008). Wnt3a-mediated formation of phosphatidylinositol 4,5-bisphosphate regulates LRP6 phosphorylation. Science 321, 1350-1353. doi: 10.1126/science.1160741

Park, K., Lee, K., Zhang, B., Zhou, T., He, X., Gao, G., et al. (2011). Identification of a novel inhibitor of the canonical Wnt pathway. Mol. Cell. Biol. 31, 3038-3051. doi: $10.1128 / \mathrm{mcb} .01211-10$

Perrody, E., Abrami, L., Feldman, M., Kunz, B., Urbé, S., and van der Goot, F. G. (2016). Ubiquitin-dependent folding of the Wnt signaling coreceptor LRP6. Elife 5:e19083. doi: 10.7554/eLife.19083

Pinson, K. I., Brennan, J., Monkley, S., Avery, B. J., and Skarnes, W. C. (2000). An LDL-receptor-related protein mediates Wnt signalling in mice. Nature 407, 535-538. doi: 10.1038/35035124

Raines, E. W. (2004). PDGF and cardiovascular disease. Cytokine Growth Factor Rev. 15, 237-254. doi: 10.1016/j.cytogfr.2004.03.004

Regard, J. B., Zhong, Z., Williams, B. O., and Yang, Y. (2012). Wnt signaling in bone development and disease: making stronger bone with Wnts. Cold Spring Harb. Perspect. Biol. 4:a007997. doi: 10.1101/cshperspect.a007997

Ren, D. N., Chen, J., Li, Z., Yan, H., Yin, Y., Wo, D., et al. (2015). LRP5/6 directly bind to Frizzled and prevent Frizzled-regulated tumour metastasis. Nat. Commun. 6:6906. doi: 10.1038/ncomms7906

Rochlani, Y., Pothineni, N. V., Kovelamudi, S., and Mehta, J. L. (2017). Metabolic syndrome: pathophysiology, management, and modulation by natural compounds. Ther. Adv. Cardiovasc. Dis. 11, 215-225. doi: 10.1177/ 1753944717711379

Saito-Diaz, K., Benchabane, H., Tiwari, A., Tian, A., Li, B., Thompson, J. J., et al. (2018). APC inhibits ligand-independent Wnt signaling by the clathrin endocytic pathway. Dev. Cell 44, 566-581.e8. doi: 10.1016/j.devcel.2018. 02.013

Sakane, H., Yamamoto, H., and Kikuchi, A. (2010). LRP6 is internalized by Dkk1 to suppress its phosphorylation in the lipid raft and is recycled for reuse. J. Cell Sci. 123(Pt 3), 360-368. doi: 10.1242/jcs.058008

Sato, A., Yamamoto, H., Sakane, H., Koyama, H., and Kikuchi, A. (2010). Wnt5a regulates distinct signalling pathways by binding to Frizzled2. EMBO J. 29, 41-54. doi: 10.1038/emboj.2009.322

Schmitt, M., Metzger, M., Gradl, D., Davidson, G., and Orian-Rousseau, V. (2015). CD44 functions in Wnt signaling by regulating LRP6 localization and activation. Cell Death Differ. 22, 677-689. doi: 10.1038/cdd. 2014.156

Semënov, M. V., Tamai, K., Brott, B. K., Kühl, M., Sokol, S., and He, X. (2001). Head inducer Dickkopf-1 is a ligand for Wnt coreceptor LRP6. Curr. Biol. 11, 951-961. doi: 10.1016/s0960-9822(01)00290-1

Semënov, M., Tamai, K., and He, X. (2005). SOST is a ligand for LRP5/LRP6 and a Wnt signaling inhibitor. J. Biol. Chem. 280, 26770-26775. doi: 10.1074/jbc. M504308200

Sezgin, E., Levental, I., Mayor, S., and Eggeling, C. (2017). The mystery of membrane organization: composition, regulation and roles of lipid rafts. Nat. Rev. Mol. Cell Biol. 18, 361-374. doi: 10.1038/nrm.2017.16

Sharma, K., Choi, S. Y., Zhang, Y., Nieland, T. J., Long, S., Li, M., et al. (2013). High-throughput genetic screen for synaptogenic factors: identification of LRP6 as critical for excitatory synapse development. Cell Rep. 5, 1330-1341. doi: 10.1016/j.celrep.2013.11.008 
Singh, R., De Aguiar, R. B., Naik, S., Mani, S., Ostadsharif, K., Wencker, D., et al. (2013a). LRP6 enhances glucose metabolism by promoting TCF7L2-dependent insulin receptor expression and IGF receptor stabilization in humans. Cell Metab. 17, 197-209. doi: 10.1016/j.cmet.2013.01.009

Singh, R., Smith, E., Fathzadeh, M., Liu, W., Go, G. W., Subrahmanyan, L., et al. (2013b). Rare nonconservative LRP6 mutations are associated with metabolic syndrome. Hum. Mutat. 34, 1221-1225. doi: 10.1002/humu.22360

Srivastava, R., Zhang, J., Go, G. W., Narayanan, A., Nottoli, T. P., and Mani, A. (2015). Impaired LRP6-TCF7L2 activity enhances smooth muscle cell plasticity and causes coronary artery disease. Cell Rep. 13, 746-759. doi: 10.1016/j.celrep. 2015.09.028

Swiatek, W., Kang, H., Garcia, B. A., Shabanowitz, J., Coombs, G. S., Hunt, D. F., et al. (2006). Negative regulation of LRP6 function by casein kinase I epsilon phosphorylation. J. Biol. Chem. 281, 12233-12241. doi: 10.1074/jbc. M510580200

Taelman, V. F., Dobrowolski, R., Plouhinec, J. L., Fuentealba, L. C., Vorwald, P. P., Gumper, I., et al. (2010). Wnt signaling requires sequestration of glycogen synthase kinase 3 inside multivesicular endosomes. Cell 143, 1136-1148. doi: 10.1016/j.cell.2010.11.034

Tahir, S. A., Yang, G., Goltsov, A., Song, K. D., Ren, C., Wang, J., et al. (2013). Caveolin-1-LRP6 signaling module stimulates aerobic glycolysis in prostate cancer. Cancer Res. 73, 1900-1911. doi: 10.1158/0008-5472.can-12-3040

Tamai, K., Semenov, M., Kato, Y., Spokony, R., Liu, C., Katsuyama, Y., et al. (2000). LDL-receptor-related proteins in Wnt signal transduction. Nature 407, 530-535. doi: 10.1038/35035117

Tamai, K., Zeng, X., Liu, C., Zhang, X., Harada, Y., Chang, Z., et al. (2004). A mechanism for Wnt coreceptor activation. Mol. Cell 13, 149-156. doi: 10.1016/ s1097-2765(03)00484-2

Tanneberger, K., Pfister, A. S., Brauburger, K., Schneikert, J., Hadjihannas, M. V., Kriz, V., et al. (2011). Amer1/WTX couples Wnt-induced formation of PtdIns(4,5)P2 to LRP6 phosphorylation. EMBO J. 30, 1433-1443. doi: 10.1038/ emboj.2011.28

Tung, E. K., Wong, B. Y., Yau, T. O., and Ng, I. O. (2012). Upregulation of the Wnt co-receptor LRP6 promotes hepatocarcinogenesis and enhances cell invasion. PLoS One 7:e36565. doi: 10.1371/journal.pone.0036565

Wan, M., Li, J., Herbst, K., Zhang, J., Yu, B., Wu, X., et al. (2011). LRP6 mediates cAMP generation by $\mathrm{G}$ protein-coupled receptors through regulating the membrane targeting of G $\alpha($ s). Sci. Signal. 4:ra15. doi: 10.1126/scisignal.2001464

Wan, M., Yang, C., Li, J., Wu, X., Yuan, H., Ma, H., et al. (2008). Parathyroid hormone signaling through low-density lipoprotein-related protein 6. Genes Dev. 22, 2968-2979. doi: 10.1101/gad.1702708

Wang, H., He, L., Ma, F., Regan, M. M., Balk, S. P., Richardson, A. L., et al. (2013). SOX9 regulates low density lipoprotein receptor-related protein 6 (LRP6) and T-cell factor 4 (TCF4) expression and Wnt/ $\beta$-catenin activation in breast cancer. J. Biol. Chem. 288, 6478-6487. doi: 10.1074/jbc.M112.419184

Wang, L., Chai, Y., Li, C., Liu, H., Su, W., Liu, X., et al. (2018). Oxidized phospholipids are ligands for LRP6. Bone Res. 6:22. doi: 10.1038/s41413-0180023-x

Wang, X., Jia, Y., Fei, C., Song, X., and Li, L. (2016). Activation/proliferationassociated protein 2 (Caprin-2) positively regulates CDK14/cyclin Y-mediated lipoprotein receptor-related protein 5 and 6 (LRP5/6) constitutive phosphorylation. J. Biol. Chem. 291, 26427-26434. doi: 10.1074/jbc.M116.744607

Wang, Y., Yin, C., Chen, Z., Li, Y., Zou, Y., Wang, X., et al. (2020). Cardiac-specific LRP6 knockout induces lipid accumulation through Drp1/CPT1b pathway in adult mice. Cell Tissue Res. 380, 143-153. doi: 10.1007/s00441-019-03 126-3
Wehrli, M., Dougan, S. T., Caldwell, K., O’Keefe, L., Schwartz, S., Vaizel-Ohayon, D., et al. (2000). arrow encodes an LDL-receptor-related protein essential for Wingless signalling. Nature 407, 527-530. doi: 10.1038/35035110

Wei, Q., Yokota, C., Semenov, M. V., Doble, B., Woodgett, J., and He, X. (2007). Rspondin 1 is a high affinity ligand for LRP6 and induces LRP6 phosphorylation and beta-catenin signaling. J. Biol. Chem. 282, 15903-15911. doi: 10.1074/jbc. M701927200

Wu, G., Huang, H., Garcia Abreu, J., and He, X. (2009). Inhibition of GSK3 phosphorylation of beta-catenin via phosphorylated PPPSPXS motifs of Wnt coreceptor LRP6. PLoS One 4:e4926. doi: 10.1371/journal.pone.0004926

Wu, Z., Wei, D., Gao, W., Xu, Y., Hu, Z., Ma, Z., et al. (2015). TPO-induced metabolic reprogramming drives liver metastasis of colorectal cancer CD110+ tumor-initiating cells. Cell Stem Cell 17, 47-59. doi: 10.1016/j.stem.2015.05.016

Xia, Z., Wu, S., Wei, X., Liao, Y., Yi, P., Liu, Y., et al. (2019). Hypoxic ER stress suppresses $\beta$-catenin expression and promotes cooperation between the transcription factors XBP1 and HIF1 $\alpha$ for cell survival. J. Biol. Chem. 294, 13811-13821. doi: 10.1074/jbc.RA119.008353

Yamamoto, H., Komekado, H., and Kikuchi, A. (2006). Caveolin is necessary for Wnt-3a-dependent internalization of LRP6 and accumulation of beta-catenin. Dev. Cell 11, 213-223. doi: 10.1016/j.devcel.2006.07.003

Yamamoto, H., Sakane, H., Yamamoto, H., Michiue, T., and Kikuchi, A. (2008). Wnt3a and Dkk1 regulate distinct internalization pathways of LRP6 to tune the activation of beta-catenin signaling. Dev. Cell 15, 37-48. doi: 10.1016/j.devcel. 2008.04.015

Ye, Z. J., Go, G. W., Singh, R., Liu, W., Keramati, A. R., and Mani, A. (2012). LRP6 protein regulates low density lipoprotein (LDL) receptor-mediated LDL uptake. J. Biol. Chem. 287, 1335-1344. doi: 10.1074/jbc.M111.295287

Yuan, Y., Xie, X., Jiang, Y., Wei, Z., Wang, P., Chen, F., et al. (2017). LRP6 is identified as a potential prognostic marker for oral squamous cell carcinoma via MALDI-IMS. Cell Death Dis. 8:e3035. doi: 10.1038/cddis.2017.433

Zeng, X., Huang, H., Tamai, K., Zhang, X., Harada, Y., Yokota, C., et al. (2008). Initiation of Wnt signaling: control of Wnt coreceptor Lrp6 phosphorylation/activation via frizzled, dishevelled and axin functions. Development 135, 367-375. doi: 10.1242/dev.013540

Zeng, X., Tamai, K., Doble, B., Li, S., Huang, H., Habas, R., et al. (2005). A dualkinase mechanism for Wnt co-receptor phosphorylation and activation. Nature 438, 873-877. doi: 10.1038/nature04185

Zhang, J., Li, Y., Liu, Q., Lu, W., and Bu, G. (2010). Wnt signaling activation and mammary gland hyperplasia in MMTV-LRP6 transgenic mice: implication for breast cancer tumorigenesis. Oncogene 29, 539-549. doi: 10.1038/onc.2009.339

Conflict of Interest: The authors declare that the research was conducted in the absence of any commercial or financial relationships that could be construed as a potential conflict of interest.

Publisher's Note: All claims expressed in this article are solely those of the authors and do not necessarily represent those of their affiliated organizations, or those of the publisher, the editors and the reviewers. Any product that may be evaluated in this article, or claim that may be made by its manufacturer, is not guaranteed or endorsed by the publisher.

Copyright (c) 2021 Jeong and Jho. This is an open-access article distributed under the terms of the Creative Commons Attribution License (CC BY). The use, distribution or reproduction in other forums is permitted, provided the original author(s) and the copyright owner(s) are credited and that the original publication in this journal is cited, in accordance with accepted academic practice. No use, distribution or reproduction is permitted which does not comply with these terms. 